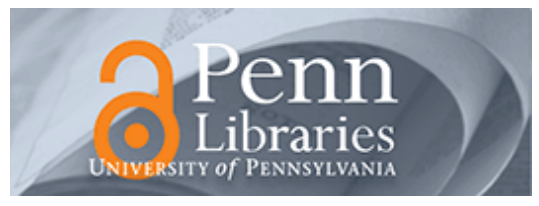

University of Pennsylvania

ScholarlyCommons

Finance Papers

Wharton Faculty Research

$10-25-2014$

\title{
Private Information and Bargaining Power in Venture Capital Financing
}

Yrjo Koskinen

University of Pennsylvania

Michael J. Rebello

Jun Wang

Follow this and additional works at: https://repository.upenn.edu/fnce_papers

Part of the Finance Commons, and the Finance and Financial Management Commons

\section{Recommended Citation}

Koskinen, Y., Rebello, M. J., \& Wang, J. (2014). Private Information and Bargaining Power in Venture Capital Financing. Journal of Economics \& Management Strategy, 23 (4), 743-775. http://dx.doi.org/ 10.1111/jems. 12072

This paper is posted at ScholarlyCommons. https://repository.upenn.edu/fnce_papers/253

For more information, please contact repository@pobox.upenn.edu. 


\title{
Private Information and Bargaining Power in Venture Capital Financing
}

\author{
Abstract \\ We model the natural evolution of private information over the life of a venture capitalist financed project. \\ In the early stages, the entrepreneur is better informed regarding the project, and when the project \\ matures, the venture capitalist has an informational advantage over the entrepreneur. Within this \\ framework, we examine how the venture capitalist's relative bargaining power affects cash flow rights and \\ investment. When the bargaining advantage lies with the entrepreneur, the project may not be screened, \\ and the venture capitalist may acquiesce to excessive initial investment but subsequently terminate the \\ project. Increased venture capitalist bargaining power encourages project screening, attenuates the \\ incentive to overinvest, and reduces the incidence of project termination subsequent to the initial \\ investment. The payoff sensitivity of venture capitalist's financing contract also increases as his \\ bargaining power improves. \\ Disciplines \\ Finance | Finance and Financial Management
}




\title{
Private Information and Bargaining Power in Venture Capital Financing*
}

\author{
Yrjö Koskinen, Michael J. Rebello and Jun Wang
}

February 2013

\footnotetext{
*Koskinen is from Boston University School of Management and CEPR (yrjo@bu.edu), Rebello is from Naveen Jindal School of Management, University of Texas at Dallas (mrebello@utdallas.edu), and Wang is from Baruch College (Jun_Wang@baruch.cuny.edu). The authors would like to thank the co-editor, two anonymous referees, Mike Fishman, Thomas Telemann, Mark Johnson, Josh Lerner, Tom Noe, Merih Sevilir, Masako Ueda, and seminar participants at Boston University, Georgia Tech, Helsinki School of Economics, Louisiana State University, Simon Fraser University, Southern Methodist University, University of Minnesota, University of South Carolina, University of Texas at Dallas, University of Wisconsin - Madison, Wake Forest University, University of Colorado at Boulder, the 17th Annual Conference on Financial Economics and Accounting in Atlanta, and Searle Center Symposium on Economics and Law of the Entrepreneur in Chicago for their comments. Michael Rebello wishes to thank SIFR for its hospitality during his visit to Stockholm when he started working on this paper. The authors are responsible for all remaining errors.
} 


\title{
Private Information and Bargaining Power in Venture Capital Financing
}

\begin{abstract}
We model the natural evolution of private information over the life of a venture capitalist financed project. In the early stages, the entrepreneur is better informed regarding the project, and when the project matures, the venture capitalist has an informational advantage over the entrepreneur. Within this framework, we examine how the venture capitalist's relative bargaining power affects cash flow rights and investment. When the bargaining advantage lies with the entrepreneur, the project may not be screened, and the venture capitalist may acquiesce to excessive initial investment but subsequently terminate the project. Increased venture capitalist bargaining power encourages project screening, attenuates the incentive to overinvest, and reduces the incidence of project termination subsequent to the initial investment. The payoff sensitivity of venture capitalist's financing contract also increases as his bargaining power improves.
\end{abstract}

JEL Classification: G24, G32, D82

Keywords: Venture capital, Private information, Bargaining power, Financial contracting, Investment distortions 


\section{Introduction}

Entrepreneurs are likely to be better informed than venture capitalists about some aspects of their projects while venture capitalists are likely to be better informed about others. ${ }^{1}$ Therefore, both venture capitalists and entrepreneurs have to contend with adverse selection during their negotiations. While adverse selection is a constant feature of the environment in which venture financing is contracted, other features of the environment fluctuate. One important feature of the contracting environment that fluctuates significantly is the flow of capital into venture funds. ${ }^{2}$ This variation in the flow of capital has been linked to dramatic fluctuations in the generosity of the terms of venture financing contracts. For example, Gompers and Lerner $(2000,2004)$ document that, when a lot of capital flows into venture funds, venture capitalists appear to be under intense pressure to invest in projects: they tend to supply capital at generous terms, giving rise to the "money chasing deals" phenomenon that leads to increased cash flow shares for the entrepreneurs.

Recognizing the important influence of adverse selection on venture financing, researchers have devoted considerable attention to understanding its influence on the cash flow rights and other features of venture capital contracts. Some have focused on the optimal design of venture financing contracts when the entrepreneur is better informed than the venture capitalist while others have examined the effect of reversing this situation. ${ }^{3}$ However, regardless of their approach to capturing adverse selection between the entrepreneur and venture capitalist, all these models share a common feature: they are all built on the assumption that the

\footnotetext{
${ }^{1}$ The evidence in Kaplan and Strömberg $(2003,2004)$ suggests that control structures in ventures are engineered to limit problems arising from both the informational advantage of entrepreneurs and the informational advantage of venture capitalists regarding [external] risks. The intense screening of projects by venture capitalists is consistent the view that entrepreneurs have an information advantage over venture capitalists regarding some aspects of their projects. The idea that venture capitalists are informed investors is consistent both with Sahlman's (1990) evidence that venture capitalists specialize in a small number of industries and thus gain a deep understanding of those industries, and Lerner's (1995) claim that venture capitalists work closely with the companies they are financing. Hellman and Puri (2000) and Bottazzi, Da Rin, and Hellmann (2008) provide evidence supporting the claim that venture capitalists are informed investors.

${ }^{2}$ In its survey "Venture capital: Money to burn," The Economist (May 27, 2000) stated "It is clear that venture capital has been prone to periods of extreme boom and bust." In its next survey on the venture capital industry (April 3, 2004), "After the drought Venture capital," The Economist claimed that "the money available for investments in start-up companies slowed to a trickle after the bubble burst."

${ }^{3}$ Dessein (2005) and Trester (1998) develop models where entrepreneurs are better informed than the venture capitalists, while Admati and Pfleiderer (1994) and Ueda (2004) develop models where entrepreneurs are only better informed than a subset of financiers. Garmaise (2007) develops a model in which the venture capitalist has an informational advantage over the entrepreneur.
} 
entrepreneur has an absolute bargaining advantage vis a vis the venture capitalist. Therefore, these models are unable to help us understand how fluctuations in the pressure on venture capitalists to invest, by changing the strength of their bargaining position in negotiations over the division of a project's surplus, will alter both entrepreneurs' and venture capitalists' incentives to exploit their informational advantages.

To fill this void, we build a model where the outcome of venture financing is shaped by both the bargaining positions of venture capitalists and entrepreneurs and adverse selection between them. In our model, the entrepreneur has an informational advantage regarding the technology employed in the venture and her project's likelihood of successful scalability from a technological perspective. The venture capitalist, in contrast, is better informed about factors that are of great importance in later stages of projects: the management, marketing, and financial know-how needed to successfully commercialize a venture. Thus, the locus of information asymmetry switches over the life of a project. ${ }^{4}$ The allocation of bargaining power between the venture capitalist and the entrepreneur varies independently of their private information and is determined by the relative scarcity of venture financing. Following the evidence of Gompers and Lerner (2000, 2004), inflow of capital to venture funds could be an empirical proxy for the relative scarcity of venture financing: when the inflow of capital to venture funds is large, we would expect the entrepreneur to possess the bargaining power. Alternatively, venture capitalist experience, proxied by the number of entrepreneurs venture capitalists have financed (see, e.g., Bengtsson and Sensoy, 2011), can measure their bargaining power: venture capitalists that have financed many entrepreneurs will have the upper hand in bargaining.

We show that many features of optimal venture financing contracts vary greatly with the allocation of bargaining power. When a venture capitalist has an absolute bargaining advantage over an entrepreneur, the optimal contract minimizes the sensitivity of the entrepreneur's claim to project profitability. Granting the venture capitalist equity or convertible claims that can be exchanged for a greater ownership share of the project is one way to generate this sort of cash flow pattern. In contrast, when the bargaining advantage shifts to the entrepreneur, the optimal contract ensures that the venture capitalist's claim is relatively insensitive to the project's performance while the entrepreneur's claim is very performance sensitive. This can be achieved by giving the entrepreneur a claim resembling levered equity and the venture capitalist a debt-like claim that can be converted into relatively modest share of common equity

The optimal investment in the project tends to be distorted in response to the adverse selection prob-

\footnotetext{
${ }^{4}$ Yung (2009) also develops a model where both the entrepreneur and the venture capitalist possess private information, but does not examine the effects of changes in bargaining power between the venture capitalist and entrepreneur.
} 
lems. The timing and nature of these distortions varies with the allocation of bargaining power. When the bargaining advantage lies with the venture capitalist, investment is distorted only during the later stages of the project, at which point he is privately informed. In this situation, the venture capitalist typically overinvests. In contrast, when the bargaining advantage switches to the entrepreneur, both early and late stage investments may be distorted. In this case the venture capitalist typically overinvests during the early stages and underinvests in the later stages. ${ }^{5}$

Another feature of venture financing that is quite sensitive to shifts in bargaining power is project screening. When the bargaining advantage lies with the venture capitalist, the optimal contract always screens out the entrepreneur if her project is of poor quality. When the bargaining advantage switches to the entrepreneur, she is often able to obtain financing even for a poor quality project. ${ }^{6}$ To compensate for this lax screening, the venture capitalist is more likely to terminate the project at a later stage. This result explains why venture capitalists are less selective and make relatively large initial investments in projects during venture financing booms. ${ }^{7}$

These dramatic variations in the venture financing contracts are the result of changes in the relative importance of venture capitalist's and entrepreneur's adverse selection problems arising from alterations in their bargaining power. When the venture capitalist has an absolute bargaining advantage, he can exploit it to limit the entrepreneur's share of the project's rents. Since the entrepreneur can only receive a relatively small payout from the project, her potential gain from misrepresenting her private information is also relatively small. Therefore, the primary force shaping the venture financing contract is the need to limit the venture capitalist's incentive to exploit his private information to capture even more of the project's value than he can based on his bargaining advantage alone. In contrast, when the bargaining advantage switches to the entrepreneur, the contract is shaped by both adverse selection problems. Now the entrepreneur can exploit her bargaining advantage to secure a large share of the project's value. It is also easier for her to leverage her private information to add to her share of value. To counter the erosion in his share of the project's value, the venture capitalist has a strong incentive to understate the project's profitability.

The optimal contracts we derive suggest that venture capitalists are able to convert their claims to a larger

\footnotetext{
${ }^{5}$ The intuition behind overinvestment during the early stage of the project is similar to De Meza and Webb's (1987) result that borrowers who have good prospects may signal their type by overinvesting.

${ }^{6}$ Manove, Padilla and Pagano (2001) find similar results in their study of banking contracts.

${ }^{7}$ For example, during the Internet boom, The Economist (May 27, 2000) reported that the venture capital industry "has become less cautious about valuations and has financed too many competing companies with dubious business plans."
} 
equity share under conditions of excess demand for venture financing or when they are highly reputable. There is some evidence for this prediction. Supporting evidence is provided by Bengtsson and Sensoy (2011), who, using U.S. data, find that experienced VCs receive weaker downside-protected cash flows i.e. cash flows that are more sensitive to project performance - than less experienced VCs. ${ }^{8}$ The optimal cash flow sharing rules in our context also invert the relation between bargaining power and risk-allocations of optimal contracts derived by Inderst and Mueller (2004).

In our analysis, the cost of screening out an entrepreneur with a poor project is endogenous. It rises with the entrepreneur's bargaining power because she is able to use it to leverage her private information. Therefore, as the entrepreneur's bargaining power rises, it becomes more costly to screen and when the cost is sufficiently high it is optimal to stop screening. Therefore, we provide a novel explanation based on endogenous screening costs for Hochberg, Ljunqvist, and Lu's (2007), and Sorensen's (2007) findings that venture capitalists with greater experience make better investments and are less likely to finance poor projects.

Our paper falls in the interstice between two streams of research on venture capital financing. The first of these two streams focuses on the design of venture capital contracts when either moral hazard (see, e.g., Casamatta (2003), Cornelli and Yosha (2003), Schmidt (2003), and Repullo and Suarez (2004)) or adverse selection (see, e.g., Admati and Pfleiderer (1994), Trester (1998), Garmaise (2007), and Dessein (2005)) drives contracting between the entrepreneur and venture capitalist. All the models in the literature on the design of venture capitalist contracts are built on the assumption that the entrepreneur has an absolute bargaining advantage vis a vis the venture capitalist. Our work departs from this literature by loosening this universal assumption regarding the allocation of bargaining power and demonstrating that variations in venture capitalist bargaining power influence the nature and intensity of the adverse selection problems surrounding their negotiations with entrepreneurs to profoundly influence the design of venture financing contracts.

The second stream of research focuses on the causes of cycles in the market for venture capital (see, e.g., Inderst and Mueller (2004), Michelacci and Suarez (2004), and Gehrig and Stenbacka (2005)). ${ }^{9}$ Like

\footnotetext{
${ }^{8}$ Cumming (2008), and Cumming and Johan (2008), using European data, find evidence that is contrary to this. In their papers VCs with more control rights or more experience are more likely to finance ventures with convertible securities - securities that have downside protection - than inexperienced VCs, who are more likely to use equity financing.

${ }^{9}$ Market conditions or bargaining power also affect the composition of venture capitalists' portfolios (Kanniainen and
} 
the models in this stream of research, our model explicitly recognizes the effect of market conditions on rent sharing in venture financing contracts. To focus on the feedback effect from venture capitalists' financing decisions to their bargaining positions, these models abstract from the influence of information asymmetry on venture financing contracts by assuming that all information asymmetry is dissipated by a fixed cost paid by venture capitalists. Our model, instead, examines in detail the how information asymmetry and the relative bargaining position of the venture capitalist together shape contracts, and abstracts from the feedback effect from venture capitalists' financing decisions to their bargaining positions. By taking a different approach than this literature on cycles, we demonstrate that the screening costs involved in resolving information asymmetry between the venture capitalist and entrepreneur are not fixed as assumed in this literature. Rather, they are endogenous and vary with relative bargaining power. Moreover, we are able to demonstrate that project terminations after initial funding are also driven by the same forces that drive venture financing cycles.

The remainder of this paper is organized as follows: In Section 2, we describe our model and present details of the informational structure, agent payoffs, and the major assumptions. Section 3 contains an analysis of the optimal cash flow sharing rules and investments. In Section 4, we demonstrate how project screening is endogenous and varies systematically with bargaining power. In section 4 , we demonstrate how the allocation of bargaining power is tied to conditions in capital markets and venture capitalist reputations. Section 5 contains a discussion our analysis and some concluding remarks. Proofs of all results are presented in the Appendix.

\section{The model}

Consider a three date model. All agents are risk neutral, and the risk-free rate is normalized to 0 . At date 0 , an entrepreneur is endowed with a project but has no capital. The entrepreneur approaches a venture capitalist (VC) for financing. If the venture capitalist agrees to provide funding, $I_{0}$ is invested at date 0 . At the next date, date 1 , another investment, $I_{1}$, is required by the project. Once again, the entrepreneur has no capital to invest in the project. Thus, the investment $I_{1}$ is also financed solely by the venture capitalist. Keuschnigg (2004), Inderst, Mueller, and Munnich (2007), and Fulghieri and Sevilir (2009)). In addition, market conditions induce over- and under-investment in private equity (Axelson, Strömberg, and Weisbach (2009)). An earlier paper by Berkovitch and Narayanan (1993) studies how timing of investments and financing choices are related to market conditions. 
These two investments generate a random cash flow $X$ at date 2, the terminal date. ${ }^{10}$ This cash flow has the two point support $\{1,1+X\}$, where $X>0$. If the venture capitalist chooses not to finance the project or if it is abandoned at date 1 , i.e., either $I_{0}=0$ or $I_{1}=0$ respectively, the project generates a cash flow of 0 , the entrepreneur is forced to obtain employment elsewhere and earns her reservation wage. For simplicity, we assume that the entrepreneur's reservation wage for the first period, from date 0 to date 1 , is 0 , and her reservation wage during the second period (date 1 to date 2 ) is $w$.

Before approaching the venture capitalist at date 0 , the entrepreneur observes a private signal $i \in\{G, B\}$ that informs her of the technological feasibility of the project. Signal $G$ indicates that the project is technically sound and has a "good" chance of succeeding, and signal $B$ indicates that the project's technology and its chances of succeeding are "bad". The ex ante probability that the entrepreneur observes signal $G$ is $\pi$. At date 1, before making the follow-on investment decision, the venture capitalist observes a private signal $j \in\{L, H\}$ that informs him of the project's economic viability. For example, the venture capitalist's signal may convey information regarding demand for the product that will be produced. Because the entrepreneur's signal and the venture capitalist's signal inform the recipients about different aspects of the project's viability, we assume that the signals $i$ and $j$ are independent. Signal $H$ is observed with probability $\phi$ and indicates that the project has a "high" likelihood of success while the signal $L$ indicates that it has a "low" likelihood of success.

The cash flow from the project is jointly determined by the investment at date 0 , the investment at date 1 , the entrepreneur's private signal realization, and the venture capitalist's private signal realization. Cash flow $1+X$ is realized with probability $P_{i}\left(I_{0}\right) P_{j}\left(I_{1}\right)$ and cash flow 1 is realized with probability $1-P_{i}\left(I_{0}\right) P_{j}\left(I_{1}\right)$ where $i \in\{G, B\}$ and $j \in\{L, H\}$. We assume that $P_{i}\left(I_{0}\right) \in[0,1]$ for all $I_{0}, P_{j}\left(I_{1}\right) \in$ $[0,1]$ for all $I_{1}$, and that both sets of functions are increasing and concave in the amount invested: $P_{i}^{\prime}>0$, $P_{i}^{\prime \prime}<0, P_{j}^{\prime}>0$, and $P_{j}^{\prime \prime}<0$.

The project is more profitable if the entrepreneur observes $G$ than if she observes $B$, that is, $P_{G}(I)>$ $P_{B}(I)$. Similarly, $P_{H}(I)>P_{L}(I)$, which implies that the project is more profitable if the venture capitalist observes $H$. We also assume that the likelihood of realizing the cash flow $1+X$ is higher after observing

\footnotetext{
${ }^{10}$ The model described here is consistent with the stylized facts about new venture financing. New ventures tend not to generate much in the way of operating profits and the primary incentive for venture capitalists to finance such ventures is to profit from the sale of the ventures rather than from capturing operating cash flows.
} 
$G$, i.e.,

$$
\frac{P_{G}^{\prime}\left(I_{0}\right)}{P_{G}\left(I_{0}\right)}>\frac{P_{B}^{\prime}\left(I_{0}\right)}{P_{B}\left(I_{0}\right)} \text { for all } I_{0}
$$

Similarly, to capture that the notion that the likelihood of project success is higher after observing $H$, we assume that

$$
\frac{P_{H}^{\prime}\left(I_{1}\right)}{P_{H}\left(I_{1}\right)}>\frac{P_{L}^{\prime}\left(I_{1}\right)}{P_{L}\left(I_{1}\right)} \text { for all } I_{1}
$$

These assumptions are similar to the single crossing property employed in much of the adverse selection literature (see, e.g., Riley (2001)).

To eliminate the uninteresting case where risk-free contracts are feasible, we assume that $w>1$ and the initial investment $I_{0}$ can be no lower than $I_{0 \text { min }}>1$. To ensure that there exist internal optimal investment levels for the date 1 investment, we assume that $P_{j}^{\prime}(0)=\infty$ and $P_{j}^{\prime}(\infty)=0$ for $j \in\{L, H\}$. Similarly, we assume that $P_{G}^{\prime}\left(I_{0 \text { min }}\right)=\infty$ and $P_{G}^{\prime}(\infty)=0$.

Let the function $T\left(\zeta, \phi, I_{0}, I_{H}, I_{L}\right)$ be defined as

$$
\begin{aligned}
& T\left(\zeta, \phi, I_{0}, I_{H}, I_{L}\right)=1-I_{0}-w \\
& +\zeta\left(\phi\left[P_{G}\left(I_{0}\right) P_{H}\left(I_{H}\right) X-I_{H}\right]+(1-\phi)\left[P_{G}\left(I_{0}\right) P_{L}\left(I_{L}\right) X-I_{L}\right]\right) \\
& +(1-\zeta)\left(\phi\left[P_{B}\left(I_{0}\right) P_{H}\left(I_{H}\right) X-I_{H}\right]+(1-\phi)\left[P_{B}\left(I_{0}\right) P_{L}\left(I_{L}\right) X-I_{L}\right]\right),
\end{aligned}
$$

This function represents project NPV when the probability of a type $G$ entrepreneur equals $\zeta$ and the probability of a type $H$ venture capitalist equals $\phi$. We assume that the project is a positive NPV undertaking from the date 0 perspective if the entrepreneur observes signal $G$, i.e., we assume that there exist $I_{0}, I_{H}$ and $I_{L}$ such that $T\left(1, \phi, I_{0}, I_{H}, I_{L}\right)>0$. Moreover, to highlight the effect of screening on project termination, we assume that if the entrepreneur observes signal $G$, there always exists a profitable follow on investment, i.e. there exists $I_{L}$ such that

$$
1+P_{G}\left(I_{0 \min }\right) P_{L}\left(I_{L}\right) X-I_{L}-w>0 .
$$

Finally, we assume that for all $I_{0}, I_{H}$ and $I_{L}$,

$$
1+P_{B}\left(I_{0}\right) P_{L}\left(I_{L}\right) X-I_{L}-w<0
$$

and

$$
T\left(\pi, \phi, I_{0}, I_{H}, I_{L}\right)-\left[1+P_{B}\left(I_{0}\right) P_{L}\left(I_{L}\right) X-I_{L}-w\right]<0 .
$$


The first of the two conditions in (5) ensures that the NPV of a follow on investment is always negative conditional on signals $B$ and $L$. The second condition ensures that, even if one does not consider the negative NPV of the follow-on date 1 investment conditional on signal realizations $B$ and $L$, the project has a negative NPV ex ante. It thereby renders infeasible pooling equilibrium outcomes where the project is financed at date 0 regardless of the entrepreneur's signal. The reason for the asymmetric nature of this condition are highlighted by the analysis in Section 4 and Appendix C, where we formally analyze the effects of loosening this restriction to examine the effect of variations in bargaining power on the screening of projects.

\subsection{Contracting}

We employ the mechanism design approach to investigate the optimal financing contracts (see, e.g., Harris and Townsend (1981)). Thus, at date 0 , the venture capitalist and entrepreneur agree on the date 0 investment, $I_{0}$, and a menu of contracts. Each contract in the menu specifies a date 1 investment level and a cash flow sharing rule. The identity of the contract that is implemented is contingent on the entrepreneur's and venture capitalist's reports of the signals they observe.

Since project NPV is negative contingent on the signal $B$, no investment is made if the entrepreneur reports $B$. Therefore, in any equilibrium, only type $G$ is financed and a menu of at most two contracts is necessary to account for the remaining signal combinations; one contract is implemented if the venture capitalist reports $H$ and the second if he reports $L .{ }^{11}$ Let the contract that is adopted after the venture capitalist reports signal $j$ be represented by $\left(I_{j}, \alpha_{j}, \gamma_{j}\right)$, where $\left(\alpha_{j}, \gamma_{j}\right)$ represents the sharing rule for the project's cash flow. ${ }^{12}$ In particular, $\alpha_{j}$ and $1-\alpha_{j}$ represent the venture capitalist's and entrepreneur's proportional shares of the cash flow 1 if the entrepreneur reports signal $j$ at date 1 . Similarly, $\gamma_{j}$ and $1-\gamma_{j}$ represent the venture capitalist's and entrepreneur's proportional shares of the incremental cash flow $X$; $\gamma_{j}$ and $1-\gamma_{j}$ are the slopes of the venture capitalist's and entrepreneur's contracts with respect to the project's cash flow, and thus capture the sensitivities of their payoffs to the project's cash flow. Given that the cash flow has a two-point support, with no loss of generality, we can use the two parameters $\alpha_{j}$ and $\gamma_{j}$ to characterize the cash flow sharing rules.

\footnotetext{
${ }^{11}$ In Appendix C, we examine contracts when the project is financed regardless of the entrepreneur's date 0 report.

${ }^{12}$ In some (pooling) outcomes the same contract is adopted regardless of the venture capitalist's report. We drop the signal subscripts when characterizing pooling contracts.
} 
It follows that, if the entrepreneur reports $G$ and the venture capitalist reports $j$, in exchange for investing $I_{0}$ and $I_{j}$, the venture capitalist receives a payoff of $\alpha_{j}\left(\alpha_{j}+\gamma_{j} X\right)$ if the realized cash flow is $1(1+X)$. One interpretation of this contract is that the venture capitalist receives a senior debt-like claim with a face value of $\alpha_{j}$ that pays him regardless of the project's outcome. He also receives an equity-like payment of $\gamma_{j} X$ if $1+X$ is realized. The entrepreneur receives the remaining cash flow, i.e., she receives $\left(1-\alpha_{j}\right)$ regardless of the outcome and an additional $\left(1-\gamma_{j}\right) X$ if the realized cash flow is $1+X$. Note that because $w>1$ and $I_{0} \geq I_{0 \min }>1$, for contracts that will induce both the venture capitalist and the entrepreneur to continue to participate in the project at date $1,0<\gamma_{j}<1$.

Let $U_{j}^{i}\left(\alpha, \gamma, I_{0}, I_{1}\right)$ represent the entrepreneur's expected payoff when the entrepreneur is type $i$ and venture capitalist is type $j$, that is, for $i \in\{G, B\}$ and $j \in\{H, L\}$.

$$
U_{j}^{i}\left(\alpha, \gamma, I_{0}, I_{1}\right) \equiv(1-\alpha)+(1-\gamma) P_{i}\left(I_{0}\right) P_{j}\left(I_{1}\right) X
$$

Similarly, let $V_{j}^{i}\left(\alpha, \gamma, I_{0}, I_{1}\right)$ represent the expected payoff to the venture capitalist when the venture capitalist is type $j$ and the entrepreneur is type $i$, that is

$$
V_{j}^{i}\left(\alpha, \gamma, I_{0}, I_{1}\right) \equiv \alpha+\gamma P_{i}\left(I_{0}\right) P_{j}\left(I_{1}\right) X
$$

where $i \in\{G, B\}$ and $j \in\{H, L\}$.

Informational problems of the nature we are examining often result in resource misallocation. The problem we are examining results in investment distortions. To put these investment distortions in context, we now establish some benchmarks. Let the conditional Pareto optimal level of investment at date 0 be represented by $I_{0}^{C P O}\left(I_{H}, I_{L}\right)$, where

$$
\phi P_{G}^{\prime}\left(I_{0}^{C P O}\right) P_{H}\left(I_{H}\right) X+(1-\phi) P_{G}^{\prime}\left(I_{0}^{C P O}\right) P_{L}\left(I_{L}\right) X-1=0 .
$$

This condition ensures that, given the date 1 investments $I_{H}$ and $I_{L}$, the marginal return on the date 0 investment equals its marginal cost. Similarly, the date 1 conditional Pareto optimal levels of investment, $I_{H}^{C P O}\left(I_{0}\right)$ and $I_{L}^{C P O}\left(I_{0}\right)$, satisfy

$$
P_{G}\left(I_{0}\right) P_{H}^{\prime}\left(I_{H}^{C P O}\right) X-1=0,
$$

and

$$
P_{G}\left(I_{0}\right) P_{L}^{\prime}\left(I_{L}^{C P O}\right) X-1=0,
$$


respectively. Each of these investment levels results in the Pareto optimal allocation of resources, given the other investment decisions. The unconditional Pareto optimal investment occurs when all date 0 and date 1 investments are set at their conditional Pareto optimal levels.

\section{Optimal Contracts}

In this section, we characterize optimal contracts for two opposite ends of bargaining power distribution: (1) the venture capitalist has an absolute bargaining advantage; and (2) the entrepreneur has an absolute bargaining advantage. We first characterize separating equilibrium outcomes where the contract terms are sensitive to the venture capitalist's signal. Then we derive pooling equilibrium outcomes where contract terms do not vary with the venture capitalist's date 1 signal. We end the section by demonstrating that these contracts are robust to date 1 renegotiation.

\subsection{Outcomes where both the entrepreneur's and venture capitalist's information are revealed}

When the venture capitalist has all the bargaining power, he will design contracts that maximize his own share of the cash flows. However, he has to pay a type $G$ entrepreneur at least her reservation wage to induce her to participate in the project. Moreover, the contracts have to induce truthful signal reports by the entrepreneur and venture capitalist. Consequently, the optimal contracts solve the following problem:

$$
\max _{\alpha_{H}, \alpha_{L}, \gamma_{H}, \gamma_{L}, I_{0}, I_{H}, I_{L}} \phi\left[V_{H}^{G}\left(\alpha_{H}, \gamma_{H}, I_{0}, I_{H}\right)-I_{H}\right]+(1-\phi)\left[V_{L}^{G}\left(\alpha_{L}, \gamma_{L}, I_{0}, I_{L}\right)-I_{L}\right]-I_{0}
$$

subject to

$$
\begin{gathered}
\phi\left[U_{H}^{G}\left(\alpha_{H}, \gamma_{H}, I_{0}, I_{H}\right)\right]+(1-\phi)\left[U_{L}^{G}\left(\alpha_{L}, \gamma_{L}, I_{0}, I_{L}\right)\right] \geq w, \\
U_{H}^{G}\left(\alpha_{H}, \gamma_{H}, I_{0}, I_{H}\right) \geq w, \\
U_{L}^{G}\left(\alpha_{L}, \gamma_{L}, I_{0}, I_{L}\right) \geq w . \\
\phi\left[U_{H}^{B}\left(\alpha_{H}, \gamma_{H}, I_{0}, I_{H}\right)\right]+(1-\phi)\left[U_{L}^{B}\left(\alpha_{L}, \gamma_{L}, I_{0}, I_{L}\right)\right] \leq w, \\
\phi w+(1-\phi)\left[U_{L}^{B}\left(\alpha_{L}, \gamma_{L}, I_{0}, I_{L}\right)\right] \leq w, \\
\phi\left[U_{H}^{B}\left(\alpha_{H}, \gamma_{H}, I_{0}, I_{H}\right)\right]+(1-\phi) w \leq w . \\
V_{H}^{G}\left(\alpha_{H}, \gamma_{H}, I_{0}, I_{H}\right)-I_{H} \geq V_{H}^{G}\left(\alpha_{L}, \gamma_{L}, I_{0}, I_{L}\right)-I_{L},
\end{gathered}
$$




$$
\begin{gathered}
V_{L}^{G}\left(\alpha_{L}, \gamma_{L}, I_{0}, I_{L}\right)-I_{L} \geq V_{L}^{G}\left(\alpha_{H}, \gamma_{H}, I_{0}, I_{H}\right)-I_{H} \\
V_{H}^{G}\left(\alpha_{H}, \gamma_{H}, I_{0}, I_{H}\right)-I_{H} \geq 0 \\
V_{L}^{G}\left(\alpha_{L}, \gamma_{L}, I_{0}, I_{L}\right)-I_{L} \geq 0 \\
\alpha_{H} \in[0,1], \alpha_{L} \in[0,1], \gamma_{H} \in[0,1], \gamma_{L} \in[0,1]
\end{gathered}
$$

Condition (12) ensures that a type $G$ entrepreneur will be willing to have her project financed by the venture capitalist because, from a date 0 perspective, the entrepreneur's expected payoff is higher than her expected reservation wage. Similarly, (13) and (14) ensure that a type $G$ entrepreneur will be willing to continue with the venture at date 1 after the venture capitalist reports signals $H$ and $L$, respectively. Meanwhile, to ensure that investing in the project has a positive NPV, the contracts have to screen out the entrepreneur if she is type $B$. Conditions (15), (16) and (17) ensure that this screening is successful because the expected value to a type $B$ entrepreneur is too low to satisfy her reservation wage at date 0 and when the venture capitalist reports his signal at date 1, respectively. Constraints (18) ((19)) ensure that the venture capitalist truthfully reports signal $H(L)$. Finally, Constraints (20) and (21) are included so that the venture capitalist finds it incentive compatible to continue with the venture at date 1.

When the bargaining advantage shifts to the entrepreneur, most of the constraints on the design of the optimal contracts remain unchanged. Specifically, the contracts have to satisfy (13) and (14) to ensure that the entrepreneur stays on with the project at date 1 if she is of type $G$. They also have to continue to satisfy (15) through (17) to ensure that a type $B$ entrepreneur does not obtain financing. To ensure continued venture capitalist participation at date 1 , the contracts have to satisfy (20) and (21), and to ensure that the contracts force the venture capitalist to truthfully reveal his private information at date 1, they have to satisfy (18) and (19). However, two modification to the constraint set are required to deal with the shift in bargaining advantage. We impose the constraint

$$
\phi\left[V_{H}^{G}\left(\alpha_{H}, \gamma_{H}, I_{0}, I_{H}\right)-I_{H}\right]+(1-\phi)\left[V_{L}^{G}\left(\alpha_{L}, \gamma_{L}, I_{0}, I_{L}\right)-I_{L}\right]-I_{0} \geq 0,
$$

and remove the constraint (12). The inclusion of (23) ensures that the venture capitalist will be willing to finance the project at date 0 , and the second change is due to the fact that the modified contract design problem calls for the maximization of the entrepreneur's expected payoff. It follows that the optimal contract designs in this case solve the following problem:

$$
\max _{\alpha_{H}, \alpha_{L}, \gamma_{H}, \gamma_{L}, I_{0}, I_{H}, I_{L}} \phi\left[U_{H}^{G}\left(\alpha_{H}, \gamma_{H}, I_{0}, I_{H}\right)\right]+(1-\phi)\left[U_{L}^{G}\left(\alpha_{L}, \gamma_{L}, I_{0}, I_{L}\right)\right]
$$


subject to the Constraints (13) through (22) and Constraint (23).

\subsubsection{Division of value}

The allocation of bargaining power completely determines the division of the project's value when the venture capitalist has the bargaining advantage. If the venture capitalist picks contracts that satisfy the entrepreneur's date 1 participation conditions, (13) and (14), as equalities, he automatically satisfies the entrepreneur's date 0 participation constraint, (12), and maximizes his share of the expected cash flow. Moreover, because cash flows with a type $B$ entrepreneur are first order stochastically dominated by cash flows with a type $G$ entrepreneur, the contracts will satisfy type $B$ 's participation constraints, (15), (16), and (17), and thus, deter type $B$ entrepreneurs. It follows that it is optimal for the venture capitalist to select contracts that satisfy the entrepreneur's date 1 participation conditions as equalities, allowing the venture capitalist to capture the project's entire NPV.

When the entrepreneur has the bargaining advantage, the venture capitalist can use her private information to blunt the entrepreneur's advantage. Like the venture capitalist, the entrepreneur will attempt to capture the project's entire NPV. However, her ability to do so is limited by the venture capitalist's informational advantage at date 1 . An optimal contract has to satisfy the type $H$ venture capitalist's truth-telling constraint, (18), to ensure that a type $H$ venture capitalist truthfully reveals his private information. Together with constraint (21), which ensures a type $L$ venture capitalist will want to invest in the project at date 1 , constraint (18), ensures that a type $H$ venture capitalist will expect to earn more than enough to invest at date 1. As the following lemma demonstrates, in some instances, in equilibrium, this premium may be large enough to ensure that the venture capitalist captures some of the surplus from the project, preventing the entrepreneur from capturing the project's entire NPV.

Lemma 1 a. If $\left(I_{0}^{*}, \alpha_{H}^{*}, \gamma_{H}^{*}, I_{H}^{*}, \alpha_{L}^{*}, \gamma_{L}^{*}, I_{L}^{*}\right)$ is a solution to the venture capitalist's problem, (11), then $U_{H}^{G}\left(\alpha_{H}^{*}, \gamma_{H}^{*}, I_{0}^{*}, I_{H}^{*}\right)=w$, and $U_{L}^{G}\left(\alpha_{L}^{*}, \gamma_{L}^{*}, I_{0}^{*}, I_{L}^{*}\right)=w$.

b. If $\left(I_{0}^{*}, \alpha_{H}^{*}, \gamma_{H}^{*}, I_{H}^{*}, \alpha_{L}^{*}, \gamma_{L}^{*}, I_{L}^{*}\right)$ is a solution to the entrepreneur's problem, (24), then

$$
\begin{array}{r}
V_{L}^{G}\left(\alpha_{L}^{*}, \gamma_{L}^{*}, I_{0}^{*}, I_{L}^{*}\right)-I_{L}^{*} \geq 0, \\
V_{H}^{G}\left(\alpha_{H}^{*}, \gamma_{H}^{*}, I_{0}^{*}, I_{H}^{*}\right)-I_{H}^{*}>0,
\end{array}
$$


and there exist solutions where

$$
\phi\left[V_{H}^{G}\left(\alpha_{H}^{*}, \gamma_{H}^{*}, I_{0}^{*}, I_{H}^{*}\right)-I_{H}^{*}\right]+(1-\phi)\left[V_{L}^{G}\left(\alpha_{L}^{*}, \gamma_{L}^{*}, I_{0}^{*}, I_{L}^{*}\right)-I_{L}^{*}\right]-I_{0}^{*}>0
$$

\subsubsection{Risk sharing}

The allocation of risk varies dramatically with changes in bargaining power. First consider the case where the venture capitalist has the bargaining power. If he observes the signal $L$ at date 1 , he will have an incentive to misreport his signal and exploit his information advantage and get the entrepreneur to accept an overvalued contract. The size of the mispricing gain that type $L$ can earn through mimicry is increasing in the riskiness of the entrepreneur's payoff following a venture capitalist report of $H$. As the extensive literature on contract design in the presence of adverse selection has established, type $L$ 's mimicry incentive is minimized by setting $1-\alpha_{H}$ to its maximum feasible level and, thus, minimizing the riskiness of the entrepreneur's payoff. ${ }^{13}$ Because this change in contract design can be made without altering the value of the contract, this approach to curbing type $L$ 's mimicry incentives is costless. Because there exists no incentive for type $H$ to mimic a type $L$ venture capitalist, in equilibrium a type $L$ venture capitalist can also receive a contract that pays off only if the high cash flow, $1+X$, is realized.

The venture capitalist's incentives reverse when the entrepreneur has the bargaining power. Now the venture capitalist has an incentive to under-report the profitability of the project after observing $H$. By doing so he can counter the entrepreneur's efforts to restrict his share of the rents: a false report of $L$ by a type $H$ venture capitalist will net him the contract for type $L$. Because cash flows are higher under type $H$, the contract will have a higher value under type $H$, earning him a mispricing gain. The optimal contract must minimize this misreporting incentive. Setting $\alpha_{L}=1$ achieves this goal by minimizing the sensitivity of the value of the venture capitalist's contract to his signal realizations. Underreporting profitability is not feasible after observing $L$. Therefore, the date 1 informational problem does not provide any incentive to restrict the design of the contract offered to the venture capitalist after he reports receipt of the signal $H$. However, minimizing the sensitivity of a type $H$ venture capitalist's payoff to the project's performance lowers the mispricing gain to a type $B$ entrepreneur from misreporting her signal. Thus, to deter mimicry by a type $B$ entrepreneur at date 0 , in equilibrium, $\alpha_{H}$ is set equal to $1 .{ }^{14}$ The difference between the optimal

\footnotetext{
${ }^{13}$ See Nachman and Noe (1994) for a detailed analysis of contract design in the presence of adverse selection.

${ }^{14}$ Given Proposition 2 and Lemma 1, it can also be shown that $\gamma_{H}>\gamma_{L}$, that is, the sensitivity of the venture capitalist's payoff
} 
allocation of risk under the two bargaining scenarios is formalized in the following proposition:

Proposition 2 a. If $\left(I_{0}^{*}, \alpha_{H}^{*}, \gamma_{H}^{*}, I_{H}^{*}, \alpha_{L}^{*}, \gamma_{L}^{*}, I_{L}^{*}\right)$ is a solution to the venture capitalist's problem, (11), then $\alpha_{H}^{*}=0$, and there exists a solution to the venture capitalist's problem where $\alpha_{L}^{*}=0$.

b. If $\left(I_{0}^{*}, \alpha_{H}^{*}, \gamma_{H}^{*}, I_{H}^{*}, \alpha_{L}^{*}, \gamma_{L}^{*}, I_{L}^{*}\right)$ is a solution to the entrepreneur's problem, (24), then $\alpha_{L}^{*}=1$, and there exists a solution where $\alpha_{H}^{*}=1$.

\subsubsection{Investment distortion}

Costlessly minimizing mimicry incentives by adopting contracts described in Propositions 2 cannot always deter mimicry. In fact, when the venture capitalist has the bargaining advantage and the following condition is satisfied, adopting the optimal cash flow sharing rules alone cannot deter mimicry:

$$
V_{L}^{G}\left(0, \gamma_{L}^{*}, I_{0}^{C P O}, I_{L}^{C P O}\right)-I_{L}^{C P O}<V_{L}^{G}\left(0, \gamma_{H}^{*}, I_{0}^{C P O}, I_{H}^{C P O}\right)-I_{H}^{C P O} .
$$

This condition will be satisfied when a type $L$ venture capitalist's cost from distorting investment to mimic type $H$ is low and, despite the adoption of the optimal cash flow sharing rules described in Proposition 2, mimicry by a type $L$ venture capitalist will inflict a large mispricing loss on the entrepreneur.

In instances where (28) holds, as is the case in many signaling equilibria, a type $H$ venture capitalist will have to augment the optimal cash flow sharing rule from Proposition 2 with a costly signal to deter mimicry. Investment distortion acts as this costly signal. Because the venture capitalist captures the entire surplus from the project, and investment distortion reduces this surplus, he has an incentive to minimize investment distortions. The cash flow ordering Assumption (2) ensures that increasing date 1 investment above its conditional Pareto Optimal level results in a higher deadweight cost to type $L$. Consequently, as demonstrated in the following proposition, to curb mimicry by type $L$, investment following the report of $H$ has to be raised above its conditional Pareto Optimal level. Because a type $H$ venture capitalist has no incentive to mimic type $L$, the date 1 investment following signal $L$ will not be distorted. Overinvestment at date 0 increases the difference between cash flow distributions of a type $H$ and $L$ venture capitalist, raising type $L$ 's mispricing gain from mimicry. This mispricing gain more than offsets the larger mimicry cost that type $L$ has to bear when too much investment is undertaken at date 0 . Consequently, if there is any investment distortion at date 0 , it is toward underinvestment.

to the project's performance is even greater when the project is expected to be more profitable. 
Similarly, investment may be distorted in equilibrium when we shift the bargaining power to the entrepreneur. Because she captures the surplus from the project, the type $G$ entrepreneur will limit value dissipation resulting from investment distortion. The cash flow ordering Assumption (1) ensures that increased date 0 investment dissipates project value faster for a type $B$ entrepreneur. Thus, by adjusting contract terms to keep the venture capitalist's payoff net of his investment constant and increasing date 0 investment, type $G$ can drive down the value type $B$ can realize from mimicry while incurring the lowest dissipation cost. Increasing investment also makes the venture capitalist's payoff less sensitive to project performance and, thus, weakens the misreporting incentive of a type $H$ venture capitalist. This provides an additional incentive to over invest at date 0 .

Now consider the date 1 investment decision. When $P_{B}\left(I_{0}^{*}\right)$ is sufficiently small, as will be the case when, contingent on signal $B$, the project has a low, investment-insensitive probability of success, a type $B$ entrepreneur has little incentive to obtain financing. Thus, the only rationale for distorting investment is to induce the venture capitalist to truthfully reveal his information. Truthful revelation can be achieved at the lowest cost by restricting date 1 investment conditional on a report of $L$ because Assumption 2 ensures that investment is more valuable to type $H$ than type $L$. Because a venture capitalist has no incentive to misreport his information after the receipt of signal $L$, it is not necessary to distort investment following receipt of the signal $H$.

When $P_{B}\left(I_{0}^{*}\right)$ is sufficiently large, the project structure is driven by a different consideration-deterring mimicry by a type $B$ entrepreneur. Consequently, instead of underinvesting, it is optimal to overinvest in the project. These results on investment distortions are formalized in the following proposition:

Proposition 3 a. Investment levels $I_{0}^{*}, I_{H}^{*}$, and $I_{L}^{*}$ that are part of a solution to the venture capitalist's problem (11) satisfy

(i) $I_{0}^{*} \leq I_{0}^{C P O}\left(I_{H}^{*}, I_{L}^{*}\right)$,

(ii) $I_{H}^{*} \geq I_{H}^{C P O}\left(I_{0}^{*}\right)$,

(iii) $I_{L}^{*}=I_{L}^{C P O}\left(I_{0}^{*}\right)$.

b. Investment levels $I_{0}^{*}, I_{H}^{*}$, and $I_{L}^{*}$ that are part of a solution to the entrepreneur's problem (24) satisfy

(i) $I_{0}^{*} \geq I_{0}^{C P O}\left(I_{H}^{*}, I_{L}^{*}\right)$, 
(ii) $I_{H}^{*}=I_{H}^{C P O}\left(I_{0}^{*}\right)$ and $I_{L}^{*} \leq I_{L}^{C P O}\left(I_{0}^{*}\right)$ if $P_{B}\left(I_{0}^{*}\right)$ is sufficiently small,

(iii) if $P_{B}\left(I_{0}^{*}\right)$ is large, there exist solutions to the entrepreneur's problem where $I_{H}^{*}>I_{H}^{C P O}\left(I_{0}^{*}\right)$ and $I_{L}^{*}>I_{L}^{C P O}\left(I_{0}^{*}\right)$.

\subsection{Outcomes where venture capitalist's information remains private}

From Proposition 3 it is clear that in equilibria featuring full information revelation the possessor of the bargaining advantage may bear deadweight costs arising from investment distortion. To limit these deadweight costs, the advantaged party may prefer a contract that is insensitive to the venture capitalist's information, i.e. a "pooling" contract whose terms do not change with the venture capitalist's signal report. Because the contract does not reveal the venture capitalist's information at date 1, the entrepreneur cannot condition her date 1 employment decision on the venture capitalist's signal. This considerably simplifies the contract design problem since it no longer needs to include any non-mimicry conditions for the venture capitalist.

When the venture capitalist has the bargaining advantage, there are many possible pooling equilibria, each of which is based on a particular set of off-equilibrium beliefs. However, only equilibria that maximize the payoff of a type $H$ venture capitalist survive most equilibrium refinements (see, e.g., Nachman and Noe (1994)). Therefore, we focus on characterizing the contracts that result in these pooling equilibria. These contracts solve the following problem:

$$
\max _{\alpha, \gamma, I_{0}, I_{1}} V_{H}^{G}\left(\alpha, \gamma, I_{0}, I_{1}\right)-I_{1}-I_{0}
$$

subject to constraints

$$
\begin{gathered}
\phi\left[U_{H}^{G}\left(\alpha, \gamma, I_{0}, I_{1}\right)\right]+(1-\phi)\left[U_{L}^{G}\left(\alpha, \gamma, I_{0}, I_{1}\right)\right] \geq w, \\
\phi\left[U_{H}^{B}\left(\alpha, \gamma, I_{0}, I_{1}\right)\right]+(1-\phi)\left[U_{L}^{B}\left(\alpha, \gamma, I_{0}, I_{1}\right)\right] \leq w, \\
\phi V_{H}^{G}\left(\alpha, \gamma, I_{0}, I_{1}\right)+(1-\phi) V_{L}^{G}\left(\alpha, \gamma, I_{0}, I_{1}\right)-I_{1}-I_{0} \geq 0 \\
V_{H}^{G}\left(\alpha, \gamma, I_{0}, I_{1}\right)-I_{1} \geq 0, \\
V_{L}^{G}\left(\alpha, \gamma, I_{0}, I_{1}\right)-I_{1} \geq 0 . \\
\alpha \in[0,1], \gamma \in[0,1] .
\end{gathered}
$$


The first constraint, (30), ensures that a type $G$ entrepreneur will accept the contract at date 0 and stay with the project at date 1 . The second constraint, (31), ensures that a type $B$ entrepreneur will not agree to the contract. The next three constraints, (32), (33) and (34), ensure that the venture capitalist will finance the project at date 0 and date 1 .

Once again, satisfying the type $G$ entrepreneur's participation constraint, (30), as an equality both maximizes the venture capitalist's payoff and deters a type $B$ entrepreneur. Because the venture capitalist's type remains hidden from the entrepreneur, the entrepreneur discounts the value of the contract to account for the possibility that the venture capitalist is type $L$. Minimizing the riskiness of the entrepreneur's payoff by maximizing $1-\alpha$ minimizes this discount. Increasing the date 0 and date 1 investment also lowers this discount because it lowers the probability of cash flow 1 . Not only are the optimal cash flow sharing rules in these pooling similar to those in the separating equilibria we have previously characterized, with the exception of the date 0 investment, even the optimal investments are similar.

When the entrepreneur has the bargaining advantage, the optimal contracts must solve the following problem:

$$
\max _{\alpha, \gamma, I_{0}, I_{1}} \phi\left[U_{H}^{G}\left(\alpha, \gamma, I_{0}, I_{1}\right)\right]+(1-\phi)\left[U_{L}^{G}\left(\alpha, \gamma, I_{0}, I_{1}\right)\right]
$$

subject to Constraints (31), (32), (33), (34), and (35).

In this case, the two forces driving the contract designs in the pooling equilibria, as is the case with the separating equilibria we have just characterized in Section 3.1, are the need to deter type $B$ entrepreneurs and limit mispricing of the contracts arising from the venture capitalist's private information. These are the same forces that drive contract designs in separating equilibria when the entrepreneur has the bargaining advantage. Therefore, as we demonstrate in the following proposition, when the entrepreneur has the bargaining advantage, the contracts in pooling equilibria closely resemble those issued in separating equilibria.

Proposition 4 a. If $\left(I_{0}^{*}, \alpha^{*}, \gamma^{*}, I_{1}^{*}\right)$ is a solution to the venture capitalist's problem (29), then

$$
\phi\left[U_{H}^{G}\left(\alpha^{*}, \gamma^{*}, I_{0}^{*}, I_{1}^{*}\right)\right]+(1-\phi)\left[U_{L}^{G}\left(\alpha^{*}, \gamma^{*}, I_{0}^{*}, I_{1}^{*}\right)\right]=w,
$$

$\alpha^{*}=0, I_{0}^{*} \geq I_{0}^{C P O}\left(I_{1}^{*}\right)$, and $I_{1}^{*} \geq I_{1}^{C P O}\left(I_{0}^{*}\right)$, where $I_{0}^{C P O}\left(I_{1}^{*}\right)$ is implicitly defined by

$$
P_{G}^{\prime}\left(I_{0}^{C P O}\right)\left[\phi P_{H}\left(I_{1}\right)+(1-\phi) P_{L}\left(I_{1}\right)\right] X-1=0
$$

and $I_{1}^{C P O}\left(I_{0}\right)$ satisfies

$$
P_{G}\left(I_{0}\right)\left[\phi P_{H}^{\prime}\left(I_{0}^{C P O}\right)+(1-\phi) P_{L}^{\prime}\left(I_{0}^{C P O}\right)\right] X-1=0 .
$$


b. If $\left(I_{0}^{*}, \alpha^{*}, \gamma^{*}, I_{1}^{*}\right)$ is a solution to the entrepreneur's problem (36), then $\alpha^{*}=1, I_{1}^{*} \leq I_{1}^{C P O}\left(I_{0}^{*}\right)$, and $I_{0}^{*} \geq I_{0}^{C P O}\left(I_{1}^{*}\right)$

\subsection{Renegotiation proofness of the equilibrium outcomes}

As the preceding equilibrium outcomes demonstrate, when the bargaining advantage lies with the venture capitalist, he captures all the surplus generated by the project. By setting contract values to achieve this division of the project's value, he is able to efficiently resolve the adverse selection problem arising from the entrepreneur's private information. Consequently, optimal contract shapes and investments are geared only towards resolving the adverse selection problem arising from the venture capitalist's private information. Therefore, the only deadweight costs arise because of investment distortions undertaken to deal with the venture capitalists' date 1 private information. It follows that, even though the contracts are designed at date 0 , they cannot be successfully renegotiated at date 1 after the venture capitalist observes his private signal.

Proposition 5 If $\left(I_{0}^{*}, \alpha_{H}^{*}, \gamma_{H}^{*}, I_{H}^{*}, \alpha_{L}^{*}, \gamma_{L}^{*}, I_{L}^{*}\right)$ is a solution to the venture capitalist's problem, then the contracts $\left(\alpha_{H}^{*}, \gamma_{H}^{*}, I_{H}^{*}\right)$ and $\left(\alpha_{L}^{*}, \gamma_{L}^{*}, I_{L}^{*}\right)$ are renegotiation proof.

Despite the possibility of both date 0 and date 1 investment distortion when the bargaining advantage rests with the entrepreneur, both the separating and pooling contracts characterized above may be renegotiation proof. That is, there is no other set of contracts that both the venture capitalist or the entrepreneur can agree on after the venture capitalist observes his private signal that will increase the payoff to at least one of them without reducing the other's payoff. When $P_{B}\left(I_{0}^{*}\right)$ is sufficiently small the contracts are renegotiation proof, because investment distortions are not driven by the need to screen out type $B$ entrepreneurs. Contracts will also tend be renegotiation proof when $P_{B}\left(I_{0}^{*}\right)$ is high so long as they do not call for overinvestment following signal $L$ at date 1 .

Proposition 6 When $P_{B}\left(I_{0}\right)$ is sufficiently low for all $I_{0}$, any solution to the entrepreneur's problem is renegotiation proof. There exist equilibria for high values of $P_{B}\left(I_{0}^{*}\right)$ where the optimal contracts are renegotiation proof. However, optimal contracts that call for overinvestment at date 1 following signal L are not renegotiation proof.

This result follows because of the distinct roles played by the date 0 and date 1 investment decisions in resolving the adverse selection problem. Because both the venture capitalist and the entrepreneur are risk 
neutral, successful renegotiation requires a switch to more profitable investment levels, that is, a reduction in investment distortion. However, the date 0 investment is irreversible and cannot be changed at the time of renegotiation. Thus, successful renegotiation rests on lowering the distortion in date 1 investment. However, whenever the distortion in date 1 investment is caused solely by the date 1 adverse selection problem, reducing investment distortion is infeasible. In contrast, overinvestment at date 1 solely to discourage type $B$ entrepreneurs from obtaining financing will support successful renegotiation.

The results in this section demonstrate that, even when the bargaining advantage lies with the entrepreneur, she may be unable to capture all the surplus generated by the project. A comparison with our results when the venture capitalist has the bargaining advantage indicates that shifts in bargaining power alter the relevance of the adverse selection problem arising from the entrepreneur's private information and its relative importance. Moreover, shifts in the bargaining power dramatically alter the nature of the adverse selection problem arising from the venture capitalist's private information. As the result, optimal contract designs, the nature of investment distortions, and their pervasiveness change along with shifts in the bargaining advantage.

\section{Bargaining power and project screening}

Thus far we have worked under the assumption that the project's ex ante NPV is negative (Condition (5)). Therefore, regardless of the allocation of the bargaining advantage, a necessary condition for every equilibrium we have examined thus far is that type $B$ entrepreneurs are screened out and do not receive financing. To highlight the interactions between bargaining power allocations and project screening, we now consider the effect of loosening Condition (5). Specifically, we allow the project's ex ante NPV to be positive, i.e., we assume there exist $I_{0}, I_{H}$ and $I_{L}$ such that $T\left(\pi, \phi, I_{0}, I_{H}, I_{L}\right)>0$. However, we continue to assume that the project NPV is negative so long as the entrepreneur is of type $B$. That is for all $I_{0}, I_{H}$ and $I_{L}$,

$$
T\left(0, \phi, I_{0}, I_{H}, I_{L}\right)<0
$$

With the loosening of Condition (5), the venture capitalist can continue to screen out type $B$ entrepreneurs as we have demonstrated thus far. However, screening is no longer a necessary condition for equilibrium since undertaking the project regardless of the entrepreneur's signal realization can generate a surplus when the project's ex ante NPV is positive. 
This change has no effect on the equilibrium outcomes when the venture capitalist has the bargaining advantage: the venture capitalist continues to offer contracts that screen out type $B$ entrepreneurs. As we demonstrated previously, a contract that keeps a type $G$ entrepreneur at her reservation wage ensures that a type $B$ entrepreneur would earn less than her reservation if she obtained financing for her project. Consequently, a type $B$ entrepreneur can be screened out at no cost when the venture capitalist has the bargaining advantage. Now consider the pooling alternative where the venture capitalist does not screen projects. By financing the entrepreneur even after she observes signal $B$, the venture capitalist lowers the profitability of the project and, thus, his expected gain from investing. Therefore, as we demonstrate in the following proposition, when compared with the alternative of screening, it is prohibitively costly to the venture capitalist to offer the entrepreneur a "pooling" contract that provides financing regardless the entrepreneur's signal. Consequently, when the venture capitalist has the bargaining advantage, even when the project's NPV is positive ex ante, type $B$ entrepreneurs will not receive financing and the primary driver of contracting is the venture capitalist's private information at date 1 . This problem is essentially the same as the one examined earlier in Section 3.

In contrast, loosening the restriction on the project's ex ante value leads to significant changes when the entrepreneur has the bargaining advantage. Under this allocation of bargaining power, as we demonstrated in the previous section, date 0 investment may have to be distorted to prevent a type $B$ entrepreneur from obtaining financing. This distortion is optimal only so long as its cost is small relative to the reduction in profitability from financing the project regardless of the entrepreneur's type. Consequently, as we demonstrate below, there exist pooling equilibria where the venture capitalist will finance the project regardless of the entrepreneur's private information. These equilibria will prevail when either $B$ signals only moderately negative NPV, i.e. $P_{B}$ is relatively high, or the ex ante probability of the signal $G, \pi$, is relatively high. For low values of $\pi$ and $P_{B}$, however, it is more cost effective to adopt contracts that deter the entrepreneur from obtaining financing after she observes the signal $B$.

While the venture capitalist may find it optimal to avoid screening out bad entrepreneurs at date 0 when $B$ signals only moderately negative NPV, he may review his decision at date 1 . Such a review will occur conditional on the venture capitalist signal $L$ since, combined with the lack of date 0 screening this signal realization is more likely to render continuation a negative NPV proposition. ${ }^{15}$ Therefore, as we demonstrate

\footnotetext{
${ }^{15}$ Note that, there will not exist an equilibrium in which the venture capitalist reviews his investment following both date 1 signal realizations since it is more efficient to screen out type $B$ at date 0 .
} 
in the following proposition, in equilibrium, the lack of date 0 screening may be accompanied by project liquidation at date 1 .

Proposition 7 Suppose that conditions (3) and (40) hold ensuring that the project's ex ante value is sufficiently high.

a. When the venture capitalist has the bargaining advantage, there exist no equilibria where the entrepreneur's project is financed regardless of her private information.

b. When the entrepreneur has the bargaining advantage, there exist equilibria where the entrepreneur obtains financing for her project regardless of her type. Further, in some of these pooling equilibria, the project may be terminated at date 1 following the receipt of the signal $L$ by the venture capitalist.

\section{Bargaining power, market conditions, and experience}

Until now we have focused on the two extreme allocations of bargaining power between the entrepreneur and venture capitalist. Moreover, we have operated with an exogenously specified allocation of bargaining power. We now demonstrate that our results are not sensitive to these simplifying assumptions. By embedding our contracting problem between entrepreneur and venture capitalist in a market for venture financing, we show that the outcomes we have characterized under these extreme assumptions are qualitatively similar to equilibrium outcomes for less extreme allocations of bargaining power that can arise endogenously.

To devise a simple market for venture capital financing, we assume that there exists a large number of entrepreneurs, each of whom has one project. All projects are identical to the project we have been examining thus far. It is common knowledge that each entrepreneur could be type $G$ with probability $\pi$. Each entrepreneur has to receive funding from one venture capitalist. There exist some experienced venture capitalists who have capital of $\$ K$, which is sufficient to fund both date 0 and date 1 investments in one project. The pool of entrepreneurs is too large to be financed by the established venture capitalists alone. There is an unlimited supply of potential venture capitalists, each of whom has no capital but can raise $\$ K$ from the capital markets at date 0 . There is no difference between new and experienced venture capitalists other than the difference in their capital endowments. Conditional on financing a project, at date 1, each venture capitalist observes signal $H$ with probability $\phi$. At date 0 , the venture capitalists compete with each 
other by offering entrepreneurs financing contracts. The market ceases to operate after date 0 . Therefore, venture capitalists who shut down their project at date 1 do not have opportunities to invest their funds in new projects.

A new venture capitalist incurs a fixed cost of $\theta \geq 0$ to raise $\$ K$. This cost may reflect the present value of the premium a new venture capitalist has to pay to investors to raise capital. ${ }^{16}$ This premium $\theta$ is likely to be higher when conditions in capital markets are tighter. Alternatively, $\theta$ can be interpreted as the cost of establishing the infrastructure necessary to become a venture capitalist. We assume that $\theta$ is smaller than project NPV. This ensures that new venture capitalists will be able to enter the market.

In equilibrium, new venture capitalists must be indifferent between raising capital to finance projects and staying out of the market. Therefore, a new venture capitalist will only finance a project if his expected payoff from doing so is at least equal to the amount he expects to invest plus the cost of financing, $\theta$. Moreover, entrepreneurs will be indifferent between obtaining financing from an experienced or a new venture capitalist. Therefore, in equilibrium, established venture capitalists will be able to offer contracts that enable them to extract as much of a project's value as new venture capitalists, i.e., experienced venture capitalists will expect to receive a rent of $\theta$ in addition to recovering the cost of their investment. An experienced venture capitalist's share of the project's value will vary directly with $\theta$. Therefore, $\theta$ is in effect a measure of the bargaining power of an experienced venture capitalist.

We can easily incorporate the effect of variations in $\theta$ into our earlier analysis by solving for contracts that provide a type $G$ entrepreneur with all the rents generated by her project in excess of $\theta$ and the cost of investment. For example, the only change that we have to make to our previous analysis to account for variations in $\theta$ on contracts that screen out type $B$ entrepreneurs and reveal the venture capitalist's date 1 signal, is to require that the value of the venture capitalist's contract exceeds $\theta$ rather than 0 , i.e., we need to change the venture capitalist's participation condition (23) which restricted his expected payoff to be non-negative to

$$
\phi\left[V_{H}^{G}\left(\alpha_{H}, \gamma_{H}, I_{0}, I_{H}\right)-I_{H}\right]+(1-\phi)\left[V_{L}^{G}\left(\alpha_{L}, \gamma_{L}, I_{0}, I_{L}\right)-I_{L}\right]-I_{0}=\theta
$$

Similarly, the only change that we have to make to our previous analysis to account for variations in $\theta$ on contracts that screen out type $B$ entrepreneurs but conceal the venture capitalist's private information, is to

\footnotetext{
${ }^{16}$ This assumption is similar to that that of Michelacci and Suarez (2004) who assume that venture capitalists may have to earn a premium on their investments.
} 
require that the contracts satisfy the following condition

$$
\phi V_{H}^{G}\left(\alpha, \gamma, I_{0}, I_{1}\right)+(1-\phi) V_{L}^{G}\left(\alpha, \gamma, I_{0}, I_{1}\right)-I_{1}-I_{0}=\theta
$$

rather than the condition (32), which we had imposed earlier to restrict the venture capitalist's expected payoff to be non-negative.

Without putting more structure on project payoffs, we cannot obtain closed form solutions for the optimal investment levels and thus, cannot express the relation between $\theta$ and the optimal contracts in closed form. Therefore, we employ numerical techniques to illustrate the effects of varying $\theta$ and some comparative statics of our model. ${ }^{17}$ Specifically, we assume that $X=300, w=11, \phi=0.3, \pi=0.5$, $P_{G}\left(I_{0}\right)=1-e^{-5 I_{0}}, P_{B}\left(I_{0}\right)=\lambda_{B}\left(1-e^{-10 I_{0}}\right), P_{H}\left(I_{1}\right)=\frac{1}{10} I_{1}^{0.42}$, and $P_{L}\left(I_{1}\right)=\frac{1}{10} I_{1}^{0.42 \lambda_{L}} .^{18}$ The parameters $\lambda_{B}=0.24$ and $\lambda_{L}=0.75$ capture the difference between cash flow distributions across entrepreneur and venture capitalist types respectively. Figure 1 plots the equilibrium outcomes for these parameter values and illustrates the effect of changes in $\theta$ on equilibrium outcomes.

If the venture capitalist has the bargaining advantage, there is only one equilibrium outcome-the type $B$ entrepreneur is screened out, and the type $H$ and type $L$ venture capitalists truthfully report their signals without need for investment distortions. Not surprisingly, this is the only equilibrium outcome when $\theta=30$, because at this value of $\theta$ the entrepreneur can only extract her reservation wage from the project, allowing an experienced venture capitalist to capture the entire surplus. As $\theta$ falls, the entrepreneur's share of the project's surplus rises, strengthening the mimicry incentives of the $B$ entrepreneur. When $\theta$ falls below 24 , the adoption of optimal cash flow sharing rules alone no longer deters mimicry and investment distortions are needed. When $\theta=0$, we arrive at the situation where the entrepreneur may capture the entire surplus from the project, i.e. the extreme case where the entrepreneur has an absolute bargaining advantage.

As is apparent from Figure 1, increasing $\pi$, the ex-ante probability that the entrepreneur is type $G$, also raises the mimicry incentives of a type $B$ entrepreneur because she can earn higher mispricing gains by

\footnotetext{
${ }^{17}$ As is clear from the numerical solutions, they are qualitatively similar to the equilibrium outcomes we have described previously. When $\theta$ is relatively small, the equilibrium contracts are qualitatively similar to those that obtain when the entrepreneur has an absolute bargaining advantage. For relatively large values of $\theta$, the equilibrium contracts are qualitatively similar to those that obtain when the venture capitalist has the absolute bargaining advantage. Therefore, the only incremental benefit from an analytical solution that incorporate the effect of $\theta$ would be to identify the precise value of $\theta$ at which contracting regime switches.

${ }^{18}$ These functions are well-behaved probability functions and satisfy Conditions (1) and (2) in the parameter value space that is graphed.
} 
mimicking. The optimal contracts depend on the strength of the mimicry incentives, and thus on the levels of both $\theta$ and $\pi$. Greater investment distortion and attendant deadweight costs are required to screen out a type $B$ entrepreneur as her mimicry incentives get stronger. For low values of $\pi$, because pooling outcomes where type $B$ entrepreneurs are not screened out generate negative NPVs, there is no alternative to screening out a type $B$ entrepreneur. However, for intermediate values of $\pi$, the loss of value from not screening out type $B$ entrepreneurs is lower than the deadweight cost associated with screening, especially since project shutdown following signal $L$ at date 1 helps reduce the deadweight losses from pooling. For high values of $\pi$, it is extremely costly to screen the entrepreneur out even at date 1 , because a type $B$ entrepreneur's gains from mimicry are extremely strong. Thus pooling without the possibility of date 1 project termination is optimal, i.e. it is optimal to finance the entrepreneur regardless of her signal and continue the project regardless of the venture capitalist's signal.

These results are consistent with the findings in Kaplan and Schoar (2005) who show that aggregate returns for venture capital funds are lower after booms, which are characterized by a large increase in venture financing (when $\theta$ is low). These results are also consistent with Gompers and Lerner's (2000) conclusion that entrepreneurs get higher cash flow shares and projects receive higher valuations when more capital flows into venture funds (when $\theta$ is low). Empirically we should also observe that when venture financing conditions are tighter (when $\theta$ is high), initial investments are relatively small compared to later stage investments. To our knowledge, this empirical implication has not been tested.

\section{Discussion and Conclusions}

We have modeled a situation where an entrepreneur seeks funds from a venture capitalist for a project while both possess private information. Early in the project's life the entrepreneur has better information regarding its prospects. Towards the project's end, the venture capitalist is better informed about the prospects. The bargaining power of the two parties vary based on the relative scarcity of venture financing. This variation is independent of the two agents' private information.

We demonstrate that, when the venture capitalist has the bargaining advantage, he is able to deny the entrepreneur a share of the project's surplus and use financing contracts that screen out entrepreneurs with poor projects. The terms of the contracts are driven primarily the venture capitalist's desire to signal private information and thus ensure that his payoffs very responsive to the project's performance. To signal positive 
information, the venture capitalist may also have a tendency to overinvest during later stages of the project.

The situation is dramatically altered when the bargaining advantage switches to the entrepreneur. Now the entrepreneur is able to appropriate most of the project's surplus. Consequently, it may no longer be possible to screen out entrepreneurs with poor projects. However, the venture capitalist may terminate the project after financing it initially. The venture capitalist may successfully use his private information to capture some of the project's surplus. Therefore, to limit the venture capitalist's surplus share, the optimal contract will ensure that his payoff is relatively insensitive to the project's payoffs and may call for underinvestment in the project's later stages.

These results demonstrate that the amount invested in the project and the nature of the entrepreneur's and the venture capitalist's claims on it are determined by the joint effects of the informational asymmetry and the distribution of bargaining power between them. The results provide a novel explanation for the fact that the investment and financing of venture-backed projects vary considerably across stages of venture capital cycles and that returns to venture capital investments vary depending on the market conditions. Further, these results provide insight into the documented systematic relationship between a venture capitalist's experience and performance.

Empirically, we expect than when venture funds receive large inflows of capital, more start-up companies receive financing, start-up investments are large, followed by increased amount of liquidations in later stages. Also the size of the later stage investments is low for those firms that manage to get financing. Entrepreneurs receive high valuations and financial contracts provide little upside for VCs. When venture funds receive small inflows of capital, we expect that fewer start-ups receive financing, start-up investments are small and there are fewer liquidations after the initial investments. The size of later stage investments is larger. The valuations that entrepreneurs receive are lower and financial contracts provide significant upside for VCs. These predictions are supported by the empirical literature (see, e.g., Gompers and Lerner (2000), Kaplan and Schoar (2005), Hochberg, Ljunqvist, and Lu (2007), Sorensen (2007), Bengtsson and Sensoy (2011)).

To derive our theoretical results, we assumed that the project has a liquidation value of 0 if it is terminated early. Our results wouldn't change qualitatively if we allowed for a positive liquidation value. The allocation of liquidation rights would largely follow bargaining power. When the venture capitalist has the bargaining advantage, allocating the entrepreneur rights to liquidation proceeds makes it more difficult to screen out type $B$ entrepreneurs. Thus, when the venture capitalist has the bargaining advantage he will 
allocate all the liquidation rights to himself. When the entrepreneur has the bargaining advantage, allocating liquidation rights to herself limits her ability to prevent type $B$ entrepreneurs from accessing financing. When excluding type $B$ entrepreneurs is of great importance, such as when the ex ante probability of an entrepreneur being type $G$ is relatively low or the ex ante project profitability is extremely low, liquidation rights will be allocated to the venture capitalist, allowing him to capture project rents and the entrepreneur to enjoy the benefits of excluding type $B$ from accessing financing. Otherwise, the entrepreneur will retain the liquidation rights, increasing the likelihood of pooling equilibria when the entrepreneur has the bargaining advantage. These allocations of liquidation rights are consistent with Kaplan and Strömberg's (2003) evidence.

In our model, we considered a project that generates only a terminal cash flow. This assumption is reasonable because the major component of the return on venture investments arises from the sale of the venture to the public or to another company, which we view as the terminal date of our model. However, we could also allow for an interim cash flow and the analyze changes in cash flow rights over the life of the project.

If the interim cash flow is uninformative, i.e. it is not dependent on either the entrepreneur's or the venture capitalist's signal, then the forces that determine the division of this cash flow are virtually identical to those of liquidation rights. Giving the entrepreneur a claim on the interim cash flow would make mimicry a dominant strategy for a type $B$ entrepreneur, and would raise the recipient's threat point in negotiations. Thus, we should expect that, as in the case of liquidation rights, the entrepreneur will only receive a claim on this cash flow when she has the bargaining advantage and pooling with type $B$ entrepreneurs is not very costly.

If the interim cash flow is dependent only on the entrepreneur's signal, the manner in which the cash flow is allocated can help screen out type $B$ entrepreneurs. To minimize the mispricing gains from mimicry to a type $B$ entrepreneur, the venture capitalist should receive a claim that is relatively insensitive to variations in the interim cash flow. This should be the case, regardless of who has the bargaining advantage. This sharing rule can be best achieved by financing projects by issuing claims to venture capitalists that have debt-like payoffs with respect to the interim cash flow. As a result, when the venture capitalist has the bargaining advantage, he will receive contracts whose sensitivity to venture performance increases over time. This result is consistent with the pattern of decreasing liquidation rights of the venture capitalist described 
in Kaplan and Strömberg (2004). Conversely, when the entrepreneur has the bargaining advantage, the evolution in the sensitivity of venture capitalist's payoffs to project performance should be less marked.

Our analysis also poses several question for future research. Based on previous research, we know that less experienced venture capitalists have a greater incentive to form syndicates to improve their screening capabilities (see Casamatta and Haritchabalet (2007)). Does the incentive to form syndicates vary over the venture capital cycle as well, since, according to our results, the propensity to screen investments varies over the cycle? Are differences in the screening propensities of venture capitalists reflected in the structures of their investment portfolios and exit strategies?

\section{References}

[1] Admati, A.R., Pfleiderer, P., 1994, Robust Financial Contracting and the Role of Venture Capitalists, Journal of Finance, 49:371-402.

[2] Axelson, U., Strömberg, P., Weisbach, M., 2009, Why are Buyouts Levered? The Financial Structure of Private Equity Funds, Journal of Finance, 64:1549-1582.

[3] Bengtsson, O., Sensoy, B.A., 2011, Investor Abilities and Financial Contracting: Evidence from Venture Capital, forthcoming, Journal of Financial Intermediation.

[4] Berkovitch, E., Narayanan, M.P., 1993, Timing of Investment and Financing Decisions in Imperfectly Competitive Financial Markets, Journal of Business, 60:219-247.

[5] Bottazzi, L., Da Rin, M., Hellmann, T., 2008, Who are the Active Investors? Evidence from Venture Capital, Journal of Financial Economics, 89:488-512.

[6] Casamatta, C., 2003, Financing and Advising: Optimal Financial Contracts with Venture Capitalists, Journal of Finance, 58:2059-2086.

[7] Casamatta, C., Haritchabalet, C., 2007, Experience, Screening and Syndication in Venture Capital Investments, Journal of Financial Intermediation, 16:368-398.

[8] Cornelli, F., Yosha, O., 2003, Stage Financing and the Role of Convertible Securities, Review of Economic Studies, 70:1-32. 
[9] Cumming, D., 2008, Contracts and Exits in Venture Capital Finance, Review of Financial Studies, 21:1947-1982.

[10] Cumming, D., Johan, S.A., 2008, Preplanned Exit Strategies in Venture Capital, European Economic Review, 52:1209-1241.

[11] De Meza, D., Webb, D., 1987, Too Much Investment: A Problem of Asymmetric Information, Quarterly Journal of Economics, 102:281-292.

[12] Dessein, W., 2005, Information and Control in Ventures and Alliances, Journal of Finance,60:25132549.

[13] Economist, 2000, Venture Capital: Money to Burn, May 27, p. 71-73.

[14] Economist, 2004, Special Report: After the Drought - Venture Capital, April 3, p. 71-74.

[15] Fernando, C., Gatchev V., Spindt, P., 2005, Wanna Dance? How Firms and Underwriters Choose Each Other, Journal of Finance, 60:2437-2469.

[16] Fulghieri, P., Sevilir, M., 2009, Size and Focus of a Venture Capitalist's Portfolio, Review of Financial Studies, 22:4643-4680.

[17] Garmaise, M., 2007, Informed Investors and the Financing of Entrepreneurial Projects, mimeo.

[18] Gehrig, T., Stenbacka, R., 2005, Venture Cycles: Theory and Evidence, in Venture Capital, Entrepreneurship, and Public Policy, eds. V. Kanniainen and C. Keuschnigg, MIT Press, Cambridge, 151-177.

[19] Gompers, P., Lerner, J., 2000, The Impact of Fund Inflows on Private Equity Valuations, Journal of Financial Economics, 55:281-325.

[20] Gompers, P., Lerner, J., 2004, The Venture Capital Cycle, MIT Press.

[21] Harris, M., Townsend, R., 1981, Resource Allocation Under Asymmetric Information, Econometrica, 49:33-64.

[22] Hellmann, T., Puri, M., 2000, The Interaction between Product Market and Financing Strategy: The Role of Venture Capital, Review of Financial Studies, 13:959-984. 
[23] Hochberg, Y., Ljungqvist, A., Lu, Y., 2007, Whom You Know Matters: Venture Capital Networks and Investment Performance, Journal of Finance, 62:251-301.

[24] Hopkins, E., 2012, Job Market Signaling of Relative Position, or Becker Married to Spence, Journal of European Economic Association, 10:290-322.

[25] Hsu, D., 2004, What Do Entrepreneurs Pay for Venture Capital Affiliation?, Journal of Finance, 59:1805-1840.

[26] Inderst, R., Mueller, H., 2004, The Effect of Capital Market Characteristics on the Value of Start-up Firms, Journal of Financial Economics, 74:319-356.

[27] Inderst, R., Mueller, H., and Munnich, F, 2007, Financing a Portfolio of Projects, Review of Financial Studies, 20:1289-1325.

[28] Kanniainen, V., Keuschnigg, C., 2004, Start-up Investment with Scarce Venture Capital Support, Journal of Banking and Finance, 28:1935-1959.

[29] Kaplan, S., Schoar, A., 2005, Private Equity Performance: Returns, Persistence and Capital Flows, Journal of Finance, 60:1791-1823.

[30] Kaplan, S., Strömberg, P., 2003, Financial Contracting Theory Meets the Real World: An Empirical Analysis of Venture Capital Contracts, Review of Economic Studies, 70: 281-316.

[31] Kaplan, S., Strömberg, P., 2004, Characteristics, Contracts and Actions: Evidence from Venture Capitalist Analyses, Journal of Finance, 59:2177-2210.

[32] Lerner, J., 1995, Venture Capitalists and the Oversight of Private Firms, Journal of Finance 50:301318.

[33] Manove, M., Padilla, A., Pagano, M., 2001, Collateral Versus Project Screening: A Model of Lazy Banks, Rand Journal of Economics, 32:726-744.

[34] Michelacci, C., Suarez, J., 2004, Business Creation and the Stock Market, Review of Economic Studies, $71,459-481$.

[35] Nachman, D., Noe, T., 1994, Optimal Design of Securities under Asymmetric Information, Review of Financial Studies, 7:1-44. 
[36] Repullo, R., Suarez, J., 2004, Venture Capital Finance: A Security Design Approach, Review of Finance, 8:75-108.

[37] Riley, J., 2001, Silver Signals: Twenty-five years of Screening and Signaling, Journal of Economic Literature, 39:432-478.

[38] Sahlman, W., 1990, The Structure and Governance of Venture Capital Organizations, Journal of Financial Economics, 27:473-521.

[39] Schmidt, K., 2003, Convertible Securities and Venture Capital Finance, Journal of Finance, 58:11391166.

[40] Sorensen, M., 2007, How Smart is Smart Money? A Two-Sided Matching Model of Venture Capital, Journal of Finance, 62:2725-2762.

[41] Trester, J., 1998, Venture Capital Contracting under Asymmetric Information, Journal of Banking and Finance, 22:675-699.

[42] Ueda, M., 2004, Banks versus Venture Capital: Project Evaluation, Screening, and Expropriation, Journal of Finance, 59:601-621.

[43] Wall Street Journal, 2002, Slowdown in Venture Capital Continues Unabated - Caution Reigns as VCs Become More Selective Amid Much Uncertainty, October 1, p. C.12.

[44] Yung, C., 2009, The Long-Run Supply and Demand for Venture Capital Funds: Information and Endogenous Entry, working paper. 


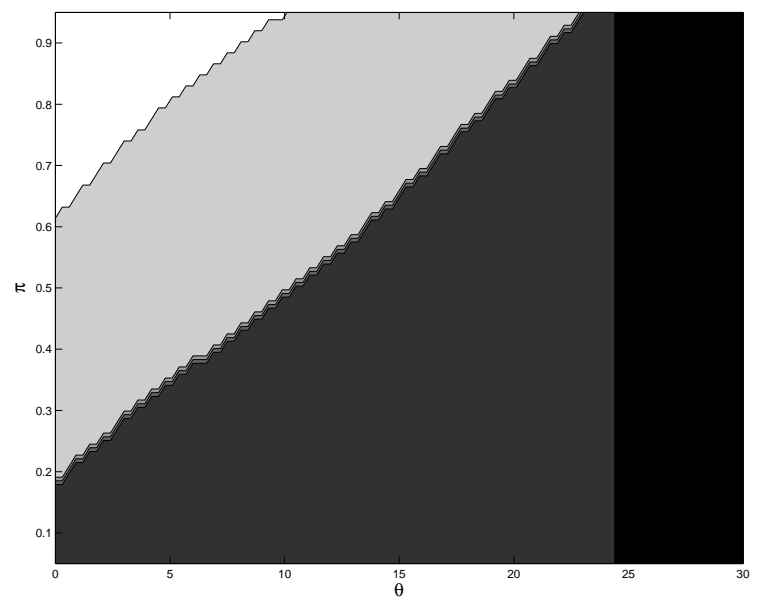

Figure 1: Equilibrium outcomes as a function of venture capitalist entry costs $(\theta)$. The four regions from the darkest to the lightest are (1) separating outcomes where type $B$ entrepreneurs are not financed and investment is not distorted, (2) separating outcomes where type $B$ entrepreneurs are not financed but investment is distorted, (3) pooling outcomes where type $B$ entrepreneurs are financed but their projects are shut down following signal $L$, and (4) pooling outcomes where type $B$ entrepreneurs are financed and projects are not terminated at date 1 . We adopt the following parameterization to generate this figure: $w=11$, $P_{G}\left(I_{0}\right)=1-e^{-2 I_{0}}, P_{B}\left(I_{0}\right)=\lambda_{B}\left(1-e^{-4 I_{0}}\right), \lambda_{B}=0.24, P_{H}\left(I_{1}\right)=\frac{1}{10} I_{1}^{0.42}, P_{L}\left(I_{1}\right)=\frac{1}{10} I_{1}^{0.42 \lambda_{L}}$, $\lambda_{L}=0.75, \phi=0.3$, and $X=300$. 


\section{Appendix A: Advantage venture capitalist}

We solve the case when the venture capitalist has the bargaining advantage in Appendix A, and the other case when the entrepreneur has the bargaining power in Appendix B.

\section{Venture capitalist separating outcomes}

To characterize the separating contracts, we first solve the venture capitalist's contract design problem after dropping the constraints (12), (15), (16), (17), (18), (20), (21), i.e., we solve the problem of (11) subject to Constraints (13), (14), (19) and (22). Then, we show that the solution to this reduced problem satisfies the omitted constraints. It follows that the solution to the simplified problem is also the solution to the venture capitalist's contract design problem.

Let $\lambda_{H}, \lambda_{L}$, and $\lambda_{V C}$ be the Lagrange multipliers for constraints (13), (14), and (19), respectively. Then the derivatives of the Lagrangian are as follows:

$$
\begin{gathered}
\frac{\partial L}{\partial \alpha_{H}}=\phi-\lambda_{H}-\lambda_{V C} \\
\frac{\partial L}{\partial \alpha_{L}}=1-\phi-\lambda_{L}+\lambda_{V C} \\
\frac{\partial L}{\partial \gamma_{H}}=\phi-\lambda_{H}-\lambda_{V C} \frac{P_{L}\left(I_{H}\right)}{P_{H}\left(I_{H}\right)} \\
\frac{\partial L}{\partial \gamma_{L}}=1-\phi-\lambda_{L}+\lambda_{V C} \\
\frac{\partial L}{\partial I_{0}}=\phi P_{G}^{\prime}\left(I_{0}\right) P_{H}\left(I_{H}\right) X+(1-\phi) P_{G}^{\prime}\left(I_{0}\right) P_{L}\left(I_{L}\right) X-1 \\
-\lambda_{V C} \gamma_{H} P_{G}^{\prime}\left(I_{0}\right) P_{L}\left(I_{H}\right) X-\lambda_{H}\left(1-\gamma_{H}\right) \frac{P_{L}\left(I_{L}\right)}{P_{H}\left(I_{H}\right)} P_{G}^{\prime}\left(I_{0}\right) P_{H}\left(I_{H}\right) X \\
\frac{\partial L}{\partial I_{H}}=-\left(\phi-\lambda_{H}-\lambda_{V C}\right)+\lambda_{H}\left[P_{G}\left(I_{0}\right) P_{H}^{\prime}\left(I_{H}\right) X-1\right] \\
+\lambda_{V C} \gamma_{H} P_{G}\left(I_{0}\right) P_{H}^{\prime}\left(I_{H}\right) X\left(\frac{P_{L}\left(I_{H}\right)}{P_{H}\left(I_{H}\right)}-\frac{P_{L}^{\prime}\left(I_{H}\right)}{P_{H}^{\prime}\left(I_{H}\right)}\right) \\
\frac{\partial L}{\partial I_{L}}=\left(1-\phi+\lambda_{V C}\right)\left[P_{G}\left(I_{0}\right) P_{L}^{\prime}\left(I_{L}\right) X-1\right]
\end{gathered}
$$

Result A.1 In every solution to the simplified problem of (11) the derivatives (A-3)-(A-7) must equal zero. 
Proof. If the boundary conditions on $\gamma_{H}, \gamma_{L}, I_{0}, I_{H}$, and $I_{L}$ do not bind, then the partial derivatives are equal to zero by the Kuhn-Tucker conditions. The boundary conditions on $I_{0}, I_{H}$, and $I_{L}$ cannot bind because of our assumptions regarding the properties of the production functions $P$. If one of the boundary constraints on $\gamma_{H}\left(\gamma_{L}\right)$ binds, then $\gamma_{H}\left(\gamma_{L}\right)$ is either 0 or 1 . If $\gamma_{H}\left(\gamma_{L}\right)$ is 0 , the venture capitalist receives the same cash flow at date 2 regardless of the project's outcome and the most he can receive is 1 . This result contradicts our assumption that the project cannot be financed using riskless debt. If $\gamma_{H}\left(\gamma_{L}\right)$ is 1 , the entrepreneur receives the same cash flow at date 2 regardless of the project's outcome, and the most she can receive is 1 . This result contradicts our assumption that $w>1$. Hence the $\gamma_{H}$ and $\gamma_{L}$ must line in the interval $(0,1)$.

Result A.2 In every solution to the simplified problem of (11) both participation constraints must bind, i.e. $\lambda_{L}^{*}>0$ and $\lambda_{H}^{*}>0$.

Proof. Because $1-\phi>0$ and $\lambda_{V C}^{*} \geq 0$, from (A-4) it follows that $\lambda_{L}^{*}>0$. Now we demonstrate that $\lambda_{H}^{*}>0$. If $\lambda_{V C}^{*}=0$, then because $\phi>0$ the desired result follows directly from (A-3). Now suppose $\lambda_{V C}^{*}>0$. From (A-3), because $\frac{P_{L}\left(I_{H}^{*}\right)}{P_{H}\left(I_{H}^{*}\right)}<1$, it follows that $\phi-\lambda_{H}^{*}-\lambda_{V C}^{*}<0$. Finally, note that Assumption (2) ensures that $\frac{P_{L}\left(I_{H}^{*}\right)}{P_{H}\left(I_{H}^{*}\right)}>\frac{P_{L}^{\prime}\left(I_{H}^{*}\right)}{P_{H}^{\prime}\left(I_{H}^{*}\right)}$. It follows that

$$
-\left(\phi-\lambda_{H}^{*}-\lambda_{V C}^{*}\right)+\lambda_{V C}^{*} \gamma_{H}^{*} P_{G}\left(I_{0}^{*}\right) P_{H}^{\prime}\left(I_{H}^{*}\right) X\left(\frac{P_{L}\left(I_{H}^{*}\right)}{P_{H}\left(I_{H}^{*}\right)}-\frac{P_{L}^{\prime}\left(I_{H}^{*}\right)}{P_{H}^{\prime}\left(I_{H}^{*}\right)}\right)>0 .
$$

It follows that, because $\frac{\partial L}{\partial I_{H}}=0,\left(\right.$ see (A-3)) it must be the case that $\lambda_{H}^{*}\left[P_{G}\left(I_{0}^{*}\right) P_{H}^{\prime}\left(I_{H}^{*}\right) X-1\right]<0$. Hence $\lambda_{H}^{*}>0$.

Result A.3 In every solution to the simplified problem of (11), $I_{H}^{*} \geq I_{H}^{C P O}\left(I_{0}^{*}\right)$.

Proof. From Result A.2, we know that $\lambda_{H}^{*}>0$ and $\phi-\lambda_{H}^{*}-\lambda_{V C}^{*}<0$, and from Assumption (2) we know that $\left.\frac{P_{L}\left(I_{H}^{*}\right)}{P_{H}\left(I_{H}^{*}\right)}-\frac{P_{L}^{\prime}\left(I_{H}^{*}\right)}{P_{H}^{\prime}\left(I_{H}^{*}\right)}\right)>0$. Therefore from (A-6) it follows that $P_{G}\left(I_{0}^{*}\right) P_{H}^{\prime}\left(I_{H}^{*}\right) X-1 \leq 0$. The claim follows directly from this result and the assumption $P_{H}^{\prime \prime}<0$.

Result A.4 In every solution to the simplified problem of $(11), I_{L}^{*}=I_{L}^{C P O}\left(I_{0}^{*}\right)$.

Proof. Because $1-\phi>0$ and $\lambda_{V C}^{*} \geq 0$, from (A-7) it follows that

$$
P_{G}\left(I_{0}^{*}\right) P_{L}^{\prime}\left(I_{L}^{*}\right) X-1=0 .
$$

The claim follows directly by comparing this expression with (10). 
Result A.5 If there exists a solution to the simplified problem of (11), there exists a solution where $\alpha_{H}^{*}=$ $\alpha_{L}^{*}=0$.

Proof. First note that because $\frac{P_{L}\left(I_{H}\right)}{P_{H}\left(I_{H}\right)}<1$, from (A-3) and (A-1) it follows that $\frac{\partial L}{\partial \alpha_{H}} \leq \frac{\partial L}{\partial \gamma_{H}}=0$. When this inequality is strict, it is clear that $\alpha_{H}^{*}=0$. When $\frac{\partial L}{\partial \alpha_{H}}=\frac{\partial L}{\partial \gamma_{H}}=0$, the venture capitalist is indifferent to all $\alpha_{H} \in[0,1]$. Therefore, $\alpha_{H}^{*}=0$ will solve the venture capitalist's problem.

Finally note that $\frac{\partial L}{\partial \alpha_{L}}=\frac{\partial L}{\partial \gamma_{H}}=1-\phi-\lambda_{L}^{*}+\lambda_{V C}^{*}=0$. Thus, the venture capitalist is indifferent to all $\alpha_{H} \in[0,1]$. It follows that $\alpha_{L}^{*}=0$ will solve the venture capitalist's $\frac{\partial L}{\partial \alpha_{L}}$.

Result A.6 In every solution to the simplified problem of (11), $I_{0}^{*} \leq I_{0}^{C P O}\left(I_{H}^{*}, I_{L}^{*}\right)$.

Proof. First note that

$$
\lambda_{V C} \gamma_{H} P_{G}^{\prime}\left(I_{0}\right) P_{L}\left(I_{H}\right) \Delta+\lambda_{H}\left(1-\gamma_{H}\right) \frac{P_{L}\left(I_{L}\right)}{P_{H}\left(I_{H}\right)} P_{G}^{\prime}\left(I_{0}\right) P_{H}\left(I_{H}\right) \Delta \geq 0 .
$$

Then, from (A-5) it must be the case that

$$
\phi P_{G}^{\prime}\left(I_{0}^{*}\right) P_{H}\left(I_{H}^{*}\right) X+(1-\phi) P_{G}^{\prime}\left(I_{0}^{*}\right) P_{L}\left(I_{L}^{*}\right) X-1 \geq 0
$$

The claim follows directly from this result and the assumption $P_{G}^{\prime \prime}<0$.

Result A.7 $V_{H}^{G}\left(\alpha_{H}^{*}, \gamma_{H}^{*}, I_{0}^{*}, I_{H}^{*}\right)-I_{H}^{*}>V_{H}^{G}\left(\alpha_{L}^{*}, \gamma_{L}^{*}, I_{0}^{*}, I_{L}^{*}\right)-I_{L}^{*}$, i.e. constraint (18) is satisfied as a strict inequality by any solution to the simplified problem of (11).

Proof. First assume that $\lambda_{V C}^{*}=0$. This implies that $I_{H}^{*}=I_{H}^{C P O}$. Substituting $\alpha_{H}^{*}, \alpha_{L}^{*}, \gamma_{H}^{*}, \gamma_{L}^{*}$ from the participation constraints (13) and (14), constraint (18) can be expressed as

$$
\begin{aligned}
& 1+P_{G}\left(I_{0}^{*}\right) P_{H}\left(I_{H}^{C P O}\right) X-w-I_{H}^{C P O} \\
\geq & 1+P_{G}\left(I_{0}^{*}\right) P_{L}\left(I_{L}^{*}\right) X-w-I_{L}^{*}+\gamma_{L}^{*} P_{G}\left(I_{0}^{*}\right) X\left[P_{H}\left(I_{L}^{*}\right)-P_{L}\left(I_{L}^{*}\right)\right] .
\end{aligned}
$$

It suffices to show that (18) holds strictly for $\gamma_{L}=1$. Substituting $\gamma_{L}=1$ into the above expression reduces it to $P_{G}\left(I_{0}^{*}\right) P_{H}\left(I_{H}^{C P O}\right) X-I_{H}^{C P O}>P_{G}\left(I_{0}^{*}\right) P_{L}\left(I_{L}^{*}\right) X-I_{L}^{*}$, which holds for any $I_{L}$.

Next assume that $\lambda_{V C}^{*}>0$. When $\lambda_{V C}^{*}>0$, we know from Result A.5 that $\alpha_{H}^{*}=0$. Now let $R:=$ $\alpha_{L}^{*}+\left(I_{H}^{*}-I_{L}^{*}\right)>0$. Because constraint (19) binds, $R+\gamma_{L}^{*} P_{G}\left(I_{0}^{*}\right) P_{L}\left(I_{L}^{*}\right) X=\gamma_{H}^{*} P_{G}\left(I_{0}^{*}\right) P_{L}\left(I_{H}^{*}\right) X$. We can write constraint (18) as

$$
\gamma_{H}^{*} P_{G}\left(I_{0}^{*}\right) P_{H}\left(I_{H}^{*}\right) X \geq R+\gamma_{L}^{*} P_{G}\left(I_{0}^{*}\right) P_{H}\left(I_{L}^{*}\right) X .
$$


Then

$$
\frac{\gamma_{H}^{*} P_{G}\left(I_{0}^{*}\right) P_{H}\left(I_{H}^{*}\right) X}{\gamma_{H}^{*} P_{G}\left(I_{0}^{*}\right) P_{L}\left(I_{H}^{*}\right) X}=\frac{P_{H}\left(I_{H}^{*}\right)}{P_{L}\left(I_{H}^{*}\right)} \geq \frac{R+\gamma_{L}^{*} P_{G}\left(I_{0}^{*}\right) P_{H}\left(I_{L}^{*}\right) X}{R+\gamma_{L}^{*} P_{G}\left(I_{0}^{*}\right) P_{L}\left(I_{L}^{*}\right) X} .
$$

We can establish our result by showing that the inequality (A-12) is strict. Let

$$
g(R)=\frac{R+\gamma_{L}^{*} P_{G}\left(I_{0}^{*}\right) P_{H}\left(I_{L}^{*}\right) X}{R+\gamma_{L}^{*} P_{G}\left(I_{0}^{*}\right) P_{L}\left(I_{L}^{*}\right) X} .
$$

Now note that $\frac{d g(R)}{d R}<0$, i.e. decreasing in $R$. This result combined with Assumption (2) results in the following inequalities:

$$
\frac{P_{H}\left(I_{H}^{*}\right)}{P_{L}\left(I_{H}^{*}\right)}>\frac{P_{H}\left(I_{L}^{*}\right)}{P_{L}\left(I_{L}^{*}\right)}>\frac{R+\gamma_{L}^{*} P_{G}\left(I_{0}^{*}\right) P_{H}\left(I_{L}^{*}\right) X}{R+\gamma_{L}^{*} P_{G}\left(I_{0}^{*}\right) P_{L}\left(I_{L}^{*}\right) X}
$$

Result A.8 A solution to the simplified problem of (11), is a solution to the original problem, i.e., constraints (12), (15), (16), (17), (20), and (21) in the venture capitalists' original problem are satisfied by any solution to the reduced problem.

Proof. As proved in Lemma A.2, constraints (13) and (14) always bind, The result for constraint (12) follows directly from that result as the left hand side of (12) is a weighted average of the left hand sides of (13) and (14). The results for constraints (15), (16), and (17) follow by first order stochastic dominance argument in addition to constraints (13) and (14) binding. The result for constraint (21) is implied by the fact that constraint (14) binds, $I_{L}^{*}=I_{L}^{C P O}\left(I_{0}^{*}\right), I_{0}^{*} \geq I_{0 \text { min }}$, and by the assumption (4). The condition (20) is satisfied because (21) is satisfied and (18) is satisfied.

Proof of Lemma 1 Part $a$, Proposition 2 Part $a$, and Proposition 3 Part $a$. Based on Results A.7 and A.8, we show that the venture capitalist's simplified problem is equivalent to his original maximization problem (11). Thus, Lemma 1 Part $a$ is proved by Result A.2. Proposition 2 Part $a$ is proved by Result A.5. Proposition 3 Part $a$ is proved by Results A.3, A.4, and A.6.

\section{Venture capitalist pooling outcomes}

To characterize the separating contracts we first solve the venture capitalist's contract design problem after dropping the constraints (31), (33), and (34), i.e., we solve the following simplified problem (29) subject to constraints (30), (32), and (35). Then, we show that the solution to this reduced problem satisfies 
the omitted constraints. It follows that the solution to the simplified problem is also the solution to the venture capitalist's contract design problem.

Let the Lagrange multipliers for constraints (30) and (32) be $\lambda_{E}$ and $\lambda_{V C}$. Then the first order conditions for the Lagrangian associated with the simplified problem (29) are

$$
\begin{gathered}
\frac{\partial L}{\partial \alpha}=1-\left(\lambda_{E}-\lambda_{V C}\right) \\
\frac{\partial L}{\partial \gamma}=1-\left(\lambda_{E}-\lambda_{V C}\right)\left[\phi+(1-\phi) \frac{P_{L}\left(I_{1}\right)}{P_{H}\left(I_{1}\right)}\right]=0 \\
\frac{\partial L}{\partial I_{0}}=\lambda_{E}\left[P_{G}^{\prime}\left(I_{0}\right)\left(\phi P_{H}\left(I_{1}\right)+(1-\phi) P_{L}\left(I_{1}\right)\right) X-1\right]-\left(1-\lambda_{E}+\lambda_{L}\right)=0 \\
\frac{\partial L}{\partial I_{1}}=\lambda_{E}\left[P_{G}\left(I_{0}\right)\left(\phi P_{H}^{\prime}\left(I_{1}\right)+(1-\phi) P_{L}^{\prime}\left(I_{1}\right)\right) X-1\right]-\left(1-\lambda_{E}+\lambda_{L}\right) \\
+\left(\lambda_{E}-\lambda_{V C}\right)(1-\phi) \gamma P_{G}\left(I_{0}\right) P_{H}^{\prime}\left(I_{1}\right) X\left[\frac{P_{L}\left(I_{1}\right)}{P_{H}\left(I_{1}\right)}-\frac{P_{L}^{\prime}\left(I_{1}\right)}{P_{H}^{\prime}\left(I_{1}\right)}\right]=0
\end{gathered}
$$

Lemma A.9 In any solution to the simplified problem (29), $\alpha^{*}=0$.

Proof. Because $\frac{P_{L}\left(I_{1}\right)}{P_{H}\left(I_{1}\right)}<1$, from (A-14) it follows that $1<\lambda_{E}-\lambda_{V C}$. Therefore, $\frac{\partial L}{\partial \alpha}<0$.

Lemma A.10 In any solution to the simplified problem (29), $I_{0}^{*} \geq I_{0}^{C P O}\left(I_{1}^{*}\right)$.

Proof. Because $\frac{P_{L}\left(I_{1}\right)}{P_{H}\left(I_{1}\right)}<1$, from (A-14) it follows that $1<\lambda_{E}-\lambda_{V C}$. Therefore, $P_{G}^{\prime}\left(I_{0}\right)\left(\phi P_{H}\left(I_{1}\right)+\right.$ $\left.(1-\phi) P_{L}\left(I_{1}\right)\right) X-1<0$.

Lemma A.11 In any solution to the simplified problem of (29), $I_{1}^{*} \geq I_{1}^{C P O}\left(I_{0}^{*}\right)$.

Proof. Because $\frac{P_{L}\left(I_{1}\right)}{P_{H}\left(I_{1}\right)}<1$, from (A-14) it follows that $1<\lambda_{E}-\lambda_{V C}$. From Assumption (2), it follows that $\frac{P_{L}\left(I_{1}\right)}{P_{H}\left(I_{1}\right)}-\frac{P_{L}^{\prime}\left(I_{1}\right)}{P_{H}^{\prime}\left(I_{1}\right)}>0$. Therefore, $P_{G}\left(I_{0}\right)\left(\phi P_{H}^{\prime}\left(I_{1}\right)+(1-\phi) P_{L}^{\prime}\left(I_{1}\right)\right) X-1<0$.

Proof of Proposition 4 Part $a$. From the proof of Lemma A.9, we have that $\lambda_{E}>0$, and thus constraint (30) binds. Constraint (15) is satisfied by first order stochastic dominance. (33) and (34) follow by assumption (4). Hence the simplified problem of (29) is equivalent to the original problem, and Lemma A.9, A.10, A.11 prove the claims. 


\section{Renegotiation proofness}

\section{Proof of Proposition 5.}

First we demonstrate that an equilibrium separating outcome cannot be successfully replaced by a renegotiated separating outcome at date 1 . To see this, note that the equilibrium separating contracts are solutions to the simplified problem (11). Renegotiated separating contracts must also satisfy constraints (13), (14), and (19). Moreover, like the equilibrium outcome, under any renegotiated separating outcome the venture capitalist must invest the conditional Pareto-optimal level of investment following signal $L$. Otherwise the venture capitalist will always be better off defecting from the renegotiated contract, investing the conditional Pareto-optimal amount and offering the entrepreneur a contract worth $w$. Finally, note that, under the equilibrium contracts, the date 1 investment distortion must be minimized conditional on the signal $H$. Therefore, under any renegotiated contract, investment conditional on the signal $H$ cannot improve on the equilibrium outcome. Because the entrepreneur and venture capitalist are both risk neutral and the cash flows under the renegotiated contract cannot exceeds the equilibrium cash flows, renegotiation cannot leave either the entrepreneur or venture capitalist better off without hurting the other. Consequently, an equilibrium separating outcome cannot be successfully replaced by a renegotiated separating outcome at date 1.

Now we establish that an equilibrium pooling outcome cannot be successfully replaced by a renegotiated pooling outcome at date 1 . To see this note that both the equilibrium outcome and the renegotiated outcome must satisfy constraints (30)-(32). Therefore, once again, a renegotiated contract cannot improve investment choices or project value. Therefore, an equilibrium pooling outcome cannot be successfully replaced by a renegotiated pooling outcome at date 1 .

To complete the proof we now demonstrate that an equilibrium separating (pooling) outcome cannot be successfully replaced by a renegotiated pooling (separating) outcome at date 1 . To see this, note that the equilibrium contract will support separation (pooling) if the expected payoff generated by the equilibrium outcome exceeds the expected payoff under the most efficient date 1 pooling (separating) outcome. The above arguments establish that a pooling (separating) outcome renegotiated at date 1 cannot improve on the most efficient pooling (separating) outcome at date 0 .

\section{Appendix B: Advantage entrepreneur}




\section{Venture capitalist separating outcomes}

We now characterize optimal contracts when the entrepreneur has the bargaining advantage. We first analyze optimal contracts when the contracts reveal the venture capitalist's private information. To characterize these contracts we solve the reduced problem of (24) with the constraints (13), (14), (16), (17), (18), (21), (23) and (22). Then we show that the solution to this reduced problem satisfies the remaining constraints ((15)), ((19)) and (20).

Let $\lambda_{G H}, \lambda_{G L}, \lambda_{B H}, \lambda_{B L}, \lambda_{V C 0}, \lambda_{L 1}$, and $\lambda_{I C H}$ be the Lagrange multipliers for constraints (13), (14), (16), (17), (23), (21), and (18), respectively. Then the derivatives of the Lagrangian for the entrepreneur's simplified problem are

$$
\begin{gathered}
\frac{\partial L}{\partial \alpha_{H}}=-\phi\left(1-\lambda_{V C 0}\right)+\lambda_{B H}-\lambda_{G H}+\lambda_{I C H} \\
\frac{\partial L}{\partial \alpha_{L}}=-(1-\phi)\left(1-\lambda_{V C 0}\right)+\lambda_{B L}-\lambda_{G L}+\lambda_{L 1}-\lambda_{I C H} \\
\frac{\partial L}{\partial \gamma_{H}}=-\phi\left(1-\lambda_{V C 0}\right)+\lambda_{B H} \frac{P_{B}\left(I_{0}\right)}{P_{G}\left(I_{0}\right)}-\lambda_{G H}+\lambda_{I C H} \\
\frac{\partial L}{\partial \gamma_{L}}=-(1-\phi)\left(1-\lambda_{V C 0}\right)+\lambda_{B L} \frac{P_{B}\left(I_{0}\right)}{P_{G}\left(I_{0}\right)}-\lambda_{G L}+\lambda_{L 1}-\lambda_{I C H} \frac{P_{H}\left(I_{L}\right)}{P_{L}\left(I_{L}\right)} \\
\frac{\partial L}{\partial I_{0}}=\lambda_{V C 0}\left[\phi P_{G}^{\prime}\left(I_{0}\right) P_{H}\left(I_{H}\right) X+(1-\phi) P_{G}^{\prime}\left(I_{0}\right) P_{L}\left(I_{L}\right) X-1\right] \\
+\lambda_{B H}\left[\frac{P_{B}\left(I_{0}\right)}{P_{G}\left(I_{0}\right)}-\frac{P_{B}^{\prime}\left(I_{0}\right)}{P_{G}^{\prime}\left(I_{0}\right)}\right] P_{G}^{\prime}\left(I_{0}\right) P_{H}\left(I_{H}\right) X \\
+\lambda_{B L}\left[\frac{P_{B}\left(I_{0}\right)}{P_{G}\left(I_{0}\right)}-\frac{P_{B}^{\prime}\left(I_{0}\right)}{P_{G}^{\prime}\left(I_{0}\right)}\right] P_{G}^{\prime}\left(I_{0}\right) P_{L}\left(I_{L}\right) X \\
+\lambda_{L 1} P_{G}^{\prime}\left(I_{0}\right) P_{L}\left(I_{L}\right) X+\lambda_{I C H} P_{G}^{\prime}\left(I_{0}\right) P_{H}\left(I_{H}\right) X\left[1-\frac{P_{H}\left(I_{L}\right)}{P_{H}\left(I_{H}\right)}\right] \\
\frac{\partial L}{\partial I_{H}}=\left(\phi \lambda_{V C 0}+\lambda_{I C H}\right)\left(P_{G}\left(I_{0}\right) P_{H}^{\prime}\left(I_{H}\right) X-1\right) \\
\frac{\partial L}{\partial I_{L}}=\left((1-\phi) \lambda_{V C 0}+\lambda_{L 1}\right)\left[P_{G}\left(I_{0}\right) P_{L}^{\prime}\left(I_{L}\right) X-1\right] \\
+\lambda_{I C H}\left[P_{G}\left(I_{0}\right) P_{L}^{\prime}\left(I_{L}\right) X\left(\frac{P_{H}\left(I_{L}\right)}{P_{L}\left(I_{L}\right)}+\gamma_{L}\left[\frac{P_{H}^{\prime}\left(I_{L}\right)}{P_{L}^{\prime}\left(I_{L}\right)}-\frac{P_{H}\left(I_{L}\right)}{P_{L}\left(I_{L}\right)}\right]\right)-1\right]
\end{gathered}
$$

Result B.1 In every solution to the entrepreneur's reduced problem, each of the FOCs, $\frac{\partial L}{\partial \gamma_{H}}, \frac{\partial L}{\partial \gamma_{L}}, \frac{\partial L}{\partial I_{0}}, \frac{\partial L}{\partial I_{H}}$, and $\frac{\partial L}{\partial I_{L}}$ must be zero.

Proof. The proof is virtually identical to that for Result A.1. 
Result B.2 There exists a solution such that $\alpha_{L}^{*}=1$.

Proof. From (B-2) and (B-4), it follows that for any solution to the entrepreneur's reduced problem

$$
\frac{\partial L}{\partial \alpha_{L}}-\frac{\partial L}{\partial \gamma_{L}}=\lambda_{B L}^{*}\left(1-\frac{P_{B}\left(I_{0}^{*}\right)}{P_{G}\left(I_{0}^{*}\right)}\right)-\lambda_{I C H}^{*}\left(1-\frac{P_{H}\left(I_{L}^{*}\right)}{P_{L}\left(I_{L}^{*}\right)}\right) .
$$

Given that $\frac{P_{B}\left(I_{0}^{*}\right)}{P_{G}\left(I_{0}^{*}\right)}<1<\frac{P_{H}\left(I_{L}^{*}\right)}{P_{L}\left(I_{L}^{*}\right)}$, and $\frac{\partial L}{\partial \gamma_{L}}=0$, it follows that $\frac{\partial L}{\partial \alpha_{L}} \geq 0$. If $\frac{\partial L}{\partial \alpha_{L}}>0$, the inequality is strict and $\alpha_{L}^{*}=1$. If $\frac{\partial L}{\partial \alpha_{L}}=0$, the entrepreneur is indifferent between all $\alpha_{L} \in[0,1]$. Therefore, $\alpha_{L}^{*}=1$ will solve the entrepreneur's problem.

Result B.3 There exists a solution such that $\alpha_{H}^{*}=1$.

Proof. From (B-1) and (B-3), it follows that in any solution to the entrepreneur's reduced problem

$$
\frac{\partial L}{\partial \alpha_{H}}-\frac{\partial L}{\partial \gamma_{H}}=\lambda_{B H}^{*}\left(1-\frac{P_{B}\left(I_{0}^{*}\right)}{P_{G}\left(I_{0}^{*}\right)}\right)
$$

Given that $\frac{P_{B}\left(I_{0}^{*}\right)}{P_{G}\left(I_{0}^{*}\right)}<1$ and $\frac{\partial L}{\partial \gamma_{H}}=0$, it follows that $\frac{\partial L}{\partial \alpha_{H}} \geq 0$. If the inequality is strict and $\alpha_{H}^{*}=1$. If $\frac{\partial L}{\partial \alpha_{H}}=0$, the entrepreneur is indifferent between all $\alpha_{H} \in[0,1]$. Therefore, $\alpha_{H}^{*}=1$ will solve the entrepreneur's problem.

Result B.4 In every solution to this problem $I_{0}^{*} \geq I_{0}^{C P O}\left(I_{H}^{*}, I_{L}^{*}\right)$.

Proof. First note that,

$$
\begin{gathered}
+\lambda_{B H}\left[\frac{P_{B}\left(I_{0}\right)}{P_{G}\left(I_{0}\right)}-\frac{P_{B}^{\prime}\left(I_{0}\right)}{P_{G}^{\prime}\left(I_{0}\right)}\right] P_{G}^{\prime}\left(I_{0}\right) P_{H}\left(I_{H}\right) X \\
+\lambda_{B L}\left[\frac{P_{B}\left(I_{0}\right)}{P_{G}\left(I_{0}\right)}-\frac{P_{B}^{\prime}\left(I_{0}\right)}{P_{G}^{\prime}\left(I_{0}\right)}\right] P_{G}^{\prime}\left(I_{0}\right) P_{L}\left(I_{L}\right) X \\
+\lambda_{L 1} P_{G}^{\prime}\left(I_{0}\right) P_{L}\left(I_{L}\right) X+\lambda_{I C H} P_{G}^{\prime}\left(I_{0}\right) P_{H}\left(I_{H}\right) X\left[1-\frac{P_{H}\left(I_{L}\right)}{P_{H}\left(I_{H}\right)}\right] \geq 0 .
\end{gathered}
$$

From (B-5) it follows then that

$$
\left[\phi P_{G}^{\prime}\left(I_{0}\right) P_{H}\left(I_{H}\right) X+(1-\phi) P_{G}^{\prime}\left(I_{0}\right) P_{L}\left(I_{L}\right) X-1\right] \leq 0 \text {. }
$$

The remainder of the proof follows directly from this result and the assumption $P_{G}^{\prime \prime}<0$.

Result B.5 In every solution to this problem $I_{H}^{*}=I_{H}^{C P O}$. 
Proof. The desired result follows directly from (B-6) which implicitly defines $I_{H}^{*}$ as this is identical to the definition of $I_{H}^{C P O}$.

Result B.6 If $P_{B}$ is sufficiently small and $I_{L}^{*}$ is part of the solution to the entrepreneur's reduced problem, then there always exist a solution to the entrepreneur's reduced problem where $I_{L}^{*} \leq I_{L}^{C P O}\left(I_{0}^{*}\right)$.

Proof. If $P_{B}$ is sufficiently small, then constraints 16) and (17) must be strict inequalities and thus $\lambda_{B H}^{*}=$ $\lambda_{B L}^{*}=0$. From Result B.2 and (B-2) it follows that, when (17) is a strict inequality and $\lambda_{B L}=0$, $(1-\phi) \lambda_{V C 0}+\lambda_{L 1} \geq \lambda_{I C H}$.

Now consider (B-7). Because $1<\frac{P_{H}(I)}{P_{L}(I)}, \gamma_{L}^{*} \in(0,1)$, and by Assumption $2, \frac{P_{H}(I)}{P_{L}(I)}-\frac{P_{H}^{\prime}(I)}{P_{L}^{\prime}(I)}<0$,

$$
\begin{aligned}
& P_{G}\left(I_{0}\right) P_{L}^{\prime}\left(I_{L}\right) X-1 \\
& \leq P_{G}\left(I_{0}\right) P_{L}^{\prime}\left(I_{L}\right) X\left(\frac{P_{H}\left(I_{L}\right)}{P_{L}\left(I_{L}\right)}+\gamma_{L}\left[\frac{P_{H}^{\prime}\left(I_{L}\right)}{P_{L}^{\prime}\left(I_{L}\right)}-\frac{P_{H}\left(I_{L}\right)}{P_{L}\left(I_{L}\right)}\right]\right)-1 .
\end{aligned}
$$

This inequality, together with $\lambda_{B L}=0,(1-\phi) \lambda_{V C 0}+\lambda_{L 1} \geq \lambda_{I C H}$ ensures that (B-7) can only be satisfied when

$$
P_{G}\left(I_{0}\right) P_{L}^{\prime}\left(I_{L}\right) X-1 \geq 0 .
$$

The remainder of the proof follows directly from the assumption $P_{L}^{\prime \prime}<0$.

Result B.7 Any solution to the entrepreneur's reduced problem strictly satisfies constraint (20).

Proof. Given the assumption that $P_{H}(I)>P_{L}(I)$ for any $I$, we have

$$
V_{H}^{G}\left(\alpha_{L}^{*}, \gamma_{L}^{*}, I_{0}^{*}, I_{L}^{*}\right)-I_{L}^{*}>V_{L}^{G}\left(\alpha_{L}^{*}, \gamma_{L}^{*}, I_{0}^{*}, I_{L}^{*}\right)-I_{L}^{*}
$$

Because (21) and (18) are satisfied in any solution to the entrepreneur's reduced problem, constraint (20) is always satisfied as strict inequality.

Result B.8 If $P_{B}$ is sufficiently small any solution to the entrepreneur's reduced problem satisfies constraint (19).

Proof. If $P_{B}$ is sufficiently small, then constraints (16) and (17) must be strict inequalities and thus $\lambda_{B H}^{*}=$ $\lambda_{B L}^{*}=0$. Moreover, from (B-3) it follows that $\lambda_{I C H}>0$, and from Lemma B.2 it then follows that $\alpha_{L}^{*}=1 \geq \alpha_{H}^{*}$. 
Let $R:=\left(1-\alpha_{H}^{*}\right)+\left(I_{H}^{*}-I_{L}^{*}\right)>0$. Now constraint (18) can be rewritten as

$$
\gamma_{H}^{*} P_{G}\left(I_{0}^{*}\right) P_{H}\left(I_{H}^{*}\right) X \geq R+\gamma_{L}^{*} P_{G}\left(I_{0}^{*}\right) P_{H}\left(I_{L}^{*}\right) X
$$

Similarly, constraint (19) can be written

$$
R+\gamma_{L}^{*} P_{G}\left(I_{0}^{*}\right) P_{L}\left(I_{L}^{*}\right) X \geq \gamma_{H}^{*} P_{G}\left(I_{0}^{*}\right) P_{L}\left(I_{H}^{*}\right) X
$$

These two inequalities imply that

$$
\frac{\gamma_{H}^{*} P_{G}\left(I_{0}^{*}\right) P_{H}\left(I_{H}^{*}\right) X}{\gamma_{H}^{*} P_{G}\left(I_{0}^{*}\right) P_{L}\left(I_{H}^{*}\right) X}=\frac{P_{H}\left(I_{H}^{*}\right)}{P_{L}\left(I_{H}^{*}\right)} \geq \frac{R+\gamma_{L}^{*} P_{G}\left(I_{0}^{*}\right) P_{H}\left(I_{L}^{*}\right) X}{R+\gamma_{L}^{*} P_{G}\left(I_{0}^{*}\right) P_{L}\left(I_{L}^{*}\right) X}
$$

We can establish the desired result by showing that the inequality (B-12) is strict. To see this, let $g(R)=$ $\frac{R+\gamma_{L}^{*} P_{G}\left(I_{0}^{*}\right) P_{H}\left(I_{L}^{*}\right) X}{R+\gamma_{L}^{*} P_{G}\left(I_{0}^{*}\right) P_{L}\left(I_{L}^{*}\right) X}$. Now note that $\frac{d g(R)}{d R}<0$, i.e. decreasing in $R$. From this result and Assumption 2 it follows that $\frac{P_{H}\left(I_{H}^{*}\right)}{P_{L}\left(I_{H}^{*}\right)}>\frac{P_{H}\left(I_{L}^{*}\right)}{P_{L}\left(I_{L}^{*}\right)}>\frac{R+\gamma_{L}^{*} P_{G}\left(I_{0}^{*}\right) P_{H}\left(I_{L}^{*}\right) X}{R+\gamma_{L}^{*} P_{G}\left(I_{0}^{*}\right) P_{L}\left(I_{L}^{*}\right) X}$.

Proof of Lemma 1 Part $b$, Proposition 2 Part $b$, and Proposition 3 Part $b$. First note that Result B.7 establishes that any solution to the entrepreneur's reduced problem solves the entrepreneur's original problem. The proof of the first claim in Lemma 1 Part $b$ follows directly from Result B.7. The second claim in Lemma 1 Part $b$ follows because, for the following parameter values the solution to the entrepreneur's problem yields the desired result: $w=11, P_{G}\left(I_{0}\right)=1-e^{-0.5 I_{0}}, P_{B}\left(I_{0}\right)=0.34\left(1-e^{-I_{0}}\right), P_{H}\left(I_{1}\right)=$ $\frac{1}{10} I_{1}^{0.35}, P_{L}\left(I_{1}\right)=\frac{1}{10} I_{1}^{0.343}, \phi=0.5, X=300$ and $\pi=0.5$. The solution in the case is $I_{0}^{*}=35.09$, $I_{H}^{*}=45.41, I_{L}^{*}=36.40, \gamma_{H}^{*}=0.7163, \gamma_{L}^{*}=0.6857$, and $\alpha_{H}^{*}=\alpha_{L}^{*}=1$.

The proof of the first claim in Proposition 2 Part $b$ follows from Result B.2 and the proof of the second claim follows from Result B.3.

The proof for Proposition 3 Part $b(i)$ follows directly from Result B.4.

The proof of Proposition 3 Part $b(i i)$ follows directly from Result B.6. The proof of the second claim in Proposition 3 Part $b(i i i)$ follows by noting that for the parameter values used to establish the second claim in Lemma 1 Part $b$, for relatively high values of $\eta$, where $P_{B}=\eta\left(1-e^{-I_{0}}\right)$ there exist equilibria where the date 1 investment levels conditional on both signal $H$ and $L$ are set above their conditional Pareto-optimal levels. 


\section{Venture capitalist pooling outcomes}

We now analyze optimal contracts when the contracts do not reveal the venture capitalist's private information. To characterize these contracts we first solve the reduced problem of (36) subject to Constraints (31), (32), (34), and (35). Then we show that the solution to this reduced problem satisfies the remaining constraint (33).

Let $\lambda_{B}, \lambda_{P V C}$, and $\lambda_{V C L}$ be the Lagrange multipliers for constraints (31), (32), and (34), respectively. Let $P_{1}\left(I_{1}\right)=\phi P_{H}\left(I_{1}\right)+(1-\phi) P_{L}\left(I_{1}\right)$. Then using a virtually identical logic in the proof of Result A.1, it can be shown that in every solution to the entrepreneur's reduced problem, each of the FOCs, $\frac{\partial L}{\partial \gamma}, \frac{\partial L}{\partial I_{0}}$, and $\frac{\partial L}{\partial I_{1}}$ must be zero. Then, the FOCs of the associated Lagrangian are

$$
\begin{gathered}
\frac{\partial L}{\partial \alpha}=-1+\lambda_{B}+\lambda_{P V C}+\lambda_{V C L}, \\
\frac{\partial L}{\partial \gamma}=-1+\lambda_{B} \frac{P_{B}\left(I_{0}\right)}{P_{G}\left(I_{0}\right)}+\lambda_{P V C}+\lambda_{V C L} \frac{P_{L}\left(I_{1}\right)}{P_{1}\left(I_{1}\right)}=0 \\
\frac{\partial L}{\partial I_{1}}=\lambda_{P V C}\left[P_{G}\left(I_{0}\right) P_{1}^{\prime}\left(I_{1}\right) X-1\right] \\
+\lambda_{V C L}\left[\gamma P_{G}\left(I_{0}\right) P_{L}^{\prime}\left(I_{1}\right) X+(1-\gamma) \frac{P_{L}\left(I_{1}\right)}{P_{1}\left(I_{1}\right)} P_{G}\left(I_{0}\right) P_{1}^{\prime}\left(I_{1}\right) X-1\right]=0 \\
\frac{\partial L}{\partial I_{0}}=\lambda_{P V C}\left[P_{G}^{\prime}\left(I_{0}\right) P_{1}\left(I_{1}\right) X-1\right]+\lambda_{V C L}\left[\gamma P_{G}^{\prime}\left(I_{0}\right) P_{L}\left(I_{1}\right) X\right] \\
+\lambda_{B}(1-\gamma) P_{G}^{\prime}\left(I_{0}\right) P_{1}\left(I_{1}\right) X\left[\frac{P_{B}\left(I_{0}\right)}{P_{G}\left(I_{0}\right)}-\frac{P_{B}^{\prime}\left(I_{0}\right)}{P_{G}^{\prime}\left(I_{0}\right)}\right]=0
\end{gathered}
$$

Result B.9 There exists a solution such that $\alpha^{*}=1$.

Proof. From (B-13) and (B-14), it follows that

$$
\frac{\partial L}{\partial \alpha}-\frac{\partial L}{\partial \gamma}=\lambda_{B}^{*}\left(1-\frac{P_{B}\left(I_{0}^{*}\right)}{P_{G}\left(I_{0}^{*}\right)}\right)-\lambda_{V C L}^{*}\left(1-\frac{P_{L}\left(I_{1}^{*}\right)}{P_{1}\left(I_{1}^{*}\right)}\right)
$$

Given that $\frac{P_{B}\left(I_{0}^{*}\right)}{P_{G}\left(I_{0}^{*}\right)}<1, \frac{P_{L}\left(I_{1}^{*}\right)}{P_{1}\left(I_{1}^{*}\right)}<1$ and $\frac{\partial L}{\partial \gamma}=0$, it follows that $\frac{\partial L}{\partial \alpha} \geq 0$. If $\frac{\partial L}{\partial \alpha}>0$, the inequality is strict and $\alpha^{*}=1$. If $\frac{\partial L}{\partial \alpha}=0$, the entrepreneur is indifferent between all $\alpha \in[0,1]$. Therefore, $\alpha^{*}=1$ will solve the entrepreneur's problem.

Result B.10 In every solution to this problem $I_{1}^{*} \leq I_{1}^{C P O}\left(I_{0}^{*}\right)$. 
Proof. Note that $P_{1}^{\prime}\left(I_{1}\right)>P_{1}^{\prime}\left(I_{1}\right) \frac{P_{L}\left(I_{1}\right)}{P_{1}\left(I_{1}\right)}>P_{L}^{\prime}\left(I_{1}\right)$. It follows that (B-15) can never be satisfied if $P_{G}\left(I_{0}\right) P_{1}^{\prime}\left(I_{1}\right) X-1<0$.

Result B.11 In every solution to this problem $I_{0}^{*} \geq I_{0}^{C P O}\left(I_{1}^{*}\right)$.

Proof. Note that $\frac{P_{B}\left(I_{0}\right)}{P_{G}\left(I_{0}\right)}-\frac{P_{B}^{\prime}\left(I_{0}\right)}{P_{G}^{\prime}\left(I_{0}\right)}>0$. It follows that

$$
\lambda_{V C L}\left[\gamma P_{G}^{\prime}\left(I_{0}\right) P_{L}\left(I_{1}\right) X\right]+\lambda_{B}(1-\gamma) P_{G}^{\prime}\left(I_{0}\right) P_{1}\left(I_{1}\right) X\left[\frac{P_{B}\left(I_{0}\right)}{P_{G}\left(I_{0}\right)}-\frac{P_{B}^{\prime}\left(I_{0}\right)}{P_{G}^{\prime}\left(I_{0}\right)}\right] \geq 0
$$

Therefore (B-16) can only be satisfied if $P_{G}^{\prime}\left(I_{0}\right) P_{1}\left(I_{1}\right) X-1 \leq 0$.

\section{Proof of Proposition 6.}

We first establish that both separating and pooling equilibria we have characterized are renegotiation proof when $P_{B}$ is sufficiently small for all $I_{0}$. First note that if $\left(\alpha_{H}^{* *}, \alpha_{L}^{* *}, \gamma_{H}^{* *}, \gamma_{L}^{* *}, I_{H}^{* *}, I_{L}^{* *}\right)$ is a renegotiated separating outcome, it must satisfy

$$
\begin{gathered}
V_{H}^{G}\left(\alpha_{H}^{* *}, \gamma_{H}^{* *}, I_{0}^{*}, I_{H}^{* *}\right)-I_{H}^{* *} \geq V_{H}^{G}\left(\alpha_{H}^{*}, \gamma_{H}^{*}, I_{0}^{*}, I_{H}^{*}\right)-I_{H}^{*} \\
V_{L}^{G}\left(\alpha_{L}^{* *}, \gamma_{L}^{* *}, I_{0}^{*}, I_{L}^{* *}\right)-I_{L}^{* *} \geq V_{L}^{G}\left(\alpha_{L}^{*}, \gamma_{L}^{*}, I_{0}^{*}, I_{L}^{*}\right)-I_{L}^{*}
\end{gathered}
$$

These two condition imply that implies that (23) in the entrepreneur's problem (24) is satisfied by the renegotiated contract. Moreover, when $P_{B}$ is sufficiently small, (16) and (17) in this problem are also strictly satisfied. Therefore, any renegotiated separating outcome must satisfy all the constraints for the problem (24). From inspection, it is also clear that any renegotiated pooling outcome must satisfy all the constraint for the entrepreneur's reduced pooling problem (36). The desired result then follows from arguments virtually identical to those used to establish Proposition 5.

The proof for the second claim follows by noting that for the parameter values used to establish the second claim in Lemma 1 Part $b$, for relatively high values of $\eta$, where $P_{B}=\eta\left(1-e^{-I_{0}}\right)$, there exist equilibria where the date 1 investment levels conditional on both signal $H$ and $L$ are set equal to their conditional Pareto-optimal levels.

Now we prove the third claim in Proposition 6. Suppose that $\left(I_{0}^{*}, \alpha_{H}^{*}, \gamma_{H}^{*}, I_{H}^{*}, \alpha_{L}^{*}, \gamma_{L}^{*}, I_{L}^{*}\right)$ solves the entrepreneur's original problem, and $I_{L}^{*}>I_{L}^{C P O}$. Now consider the following candidate renegotiation contracts, $\left(I_{0}^{*}, \alpha_{H}^{*}, \gamma_{H}^{*}, I_{L}^{*}, \alpha_{L}^{*}, \gamma_{L}^{* *}, I_{L}^{* *}\right)$, where $I_{0}$ is fixed at $I_{0}^{*}, I_{L}^{* *}=I_{L}^{*}-\epsilon>I_{L}^{C P O}, \alpha_{L}^{* *}=\alpha_{L}^{*}$, and the contract terms contingent on the signal $H$ remain unchanged. To ensure that $V_{L}^{G}\left(\alpha_{L}^{*}, \gamma_{L}^{* *}, I_{0}^{*}, I_{L}^{* *}\right)-I_{L}^{* *}=$ 
$V_{L}^{G}\left(\alpha_{L}^{*}, \gamma_{L}^{*}, I_{0}^{*}, I_{L}^{*}\right)-I_{L}^{*}$, for sufficiently small $\epsilon$, it must be the case that

$$
\frac{\partial \gamma}{\partial I_{L}}=\frac{1-P_{G}\left(I_{0}^{*}\right) P_{L}^{\prime}\left(I_{L}^{*}\right) \gamma_{L}^{*} X}{P_{G}\left(I_{0}^{*}\right) P_{L}\left(I_{L}^{*}\right) \gamma_{L}^{*} X}
$$

However this implies that

$$
\begin{aligned}
& \frac{\partial V_{H}^{G}\left(\alpha_{L}^{*}, \gamma_{L}^{*}, I_{0}^{*}, I_{L}^{*}\right)-I_{L}^{*}}{\partial I_{L}} \\
& =P_{H}\left(I_{L}^{*}\right)-P_{L}\left(I_{L}^{*}\right)-P_{G}\left(I_{0}^{*}\right) X\left[P_{L}\left(I_{L}^{*}\right) P_{H}^{\prime}\left(I_{L}^{*}\right)-P_{L}^{\prime}\left(I_{L}^{*}\right) P_{H}\left(I_{L}^{*}\right)\right] .
\end{aligned}
$$

By (2) this expression is positive if $I_{L}$ is falling. This implies that the decrease in $I_{L}$ embodied in the candidate contracts ensures that the following constraint in the renegotiation problem is satisfied:

$$
V_{H}^{G}\left(\alpha_{H}^{* *}, \gamma_{H}^{* *}, I_{0}^{*}, I_{H}^{* *}\right)-I_{H}^{* *} \geq V_{H}^{G}\left(\alpha_{L}^{* *}, \gamma_{L}^{* *}, I_{0}^{*}, I_{L}^{* *}\right)-I_{L}^{* *}
$$

The remaining constraints are satisfied by construction. The proof is completed by noting that because $I_{L}^{*}>I_{L}^{C P O}$ and the venture capitalist's expected payoff is unchanged following signal $L$ under the candidate solution, the entrepreneur's payoff must be higher. 